\title{
EL AVISO PREVIO Y EL DERECHO DE ACCIÓN EN EL SISTEMA DE SALUD CUBANO. PANORÁMICA ACTUAL EN LA PRIMERA DÉCADA DEL SIGLO XXI
}

\author{
Noria Oduardo Hernández \\ Alcides Francisco Antúnez Sánchez \\ Universidad de Granma. República de Cuba
}

http://dx.doi.org/10.5209/rev_NOMA.2012.41777

\begin{abstract}
Resumen: El trabajo destaca una situación de controversia muy álgida entre la decisión tomada por un organismo de la Administración Pública, en este caso el Ministerio de Salud, en torno a lo que se establece en las normativas jurídicas laboral para el cese de la relación jurídica laboral. En este caso la competencia y la jurisdicción son del Ministerio de Trabajo y Seguridad Social. Se significan las irregularidades que ocurren en este proceso, y el estado de indefensión en que se encuentran los trabajadores, al acudir a la vía prejudicial y judicial sin una posible solución adecuada a su pretensión, en torno a las políticas decisorias tomadas por parte del Estado en especial con este sector profesional. Nos apoyamos para ejecutar este trabajo en los métodos investigativos como la entrevista, la encuesta a profesionales y especialistas del área de capital humano de la salud, la revisión bibliográfica de disposiciones y normas generales y particulares en torno a la institución jurídica que se investigó, el derecho comparado, el método exegético jurídico, el holístico; que nos permitió arribar a las conclusiones que les proponemos en este articulo.
\end{abstract}

Palabras clave: salud, aviso previo, derecho de acción, relación juridica laboral, vinculo laboral, tutela juridica.

The previous notice and the right side of action in the System of Cuban Health. Panoramic current in the first decade of the XXI Century

\begin{abstract}
The work highlights a situation of very algid controversy between the taken decision for an organism of the public administration, in this marry the ministry of health, about which is established in the normative juridical labor thing for the cease of the ljuridica| report labor, in this marry the competence and the jurisdiction are of the Department of Labor and social security. They mean to him the irregularities that occur in this prosecute, and the state of defenselessness in which find to him the herons, to the resorts to the pre-judicial and judicial path without a possible appropriate solution to your claim, about the decisory taken politicses of the state specially with this professional sector. We lean to execute this work in the investigative methods as the interview, the inquiry to professional and specialist of the area of human capital of the health, the bibliographical revision of dispositions and general and particular norms about the ljuridica| institution that it is investigated, the comparative law of jurisprudence, the expository juridical method, the |holístico|
\end{abstract}

Keywords:

SUMARIO: Introducción | 1. Tutela jurídica de la terminación del vínculo laboral | 2. El aviso previo y el derecho de acción en la legislación laboral vigente | 3. Conclusiones | 4. Recomendaciones | 5. Bibliografía 


\section{INTRODUCCION}

Nuestra principal fuente de ingresos es el trabajo, lugar donde podemos pasar, prácticamente, un cuarto de nuestra vida. Entre un trabajador y su empleador se establece un nexo generador de derechos y obligaciones para ambas partes en tanto el primero se encuentra en la entidad laboral dentro de la jornada de trabajo, tiempo y espacio en el que se estará sujeto a la jurisdicción y competencia del empleador. No obstante el trabajador conserva el vínculo fuera del ámbito laboral de la entidad, nexo que genera para él derechos aunque no obligaciones, al no encontrarse dentro de la esfera de competencia del empleador.

Las relaciones entre el empleado y su empleador son objeto de tutela jurídica, amén de la necesidad de regular la forma en que se inicia, se formaliza, modifica o termina la relación jurídica laboral con la entidad, así como proteger la continuidad de la producción y prestación de servicios o cumplimiento del objeto social en particular; y los derechos y deberes que adquieren ambas partes de la relación.

El fundamento del surgimiento, modificación y terminación del vínculo laboral con una entidad, debe radicar en el libre ejercicio de la voluntad, tanto del empleado como del empleador; voluntad que no necesariamente ha de ser coincidente, aunque la terminación de la relación jurídica laboral puede obedecer a otros motivos de carácter objetivo, previstos por la legislación.

Es común encontrar en legislaciones extranjeras el reconocimiento del contrato de trabajo como única vía para formalizar la relación jurídica laboral, por lo tanto le otorgan a ésta las características y elementos que pueden distinguir al contrato de trabajo, asimilando, de la misma manera, las causas de terminación del contrato de trabajo como causas para dar por terminada la relación jurídica laboral. Al formalizarse la relación laboral en virtud de un contrato de trabajo, su terminación define el cese del vínculo laboral.

Como resultado de las luchas y reclamos de la clase obrera, a nivel mundial, se ha reconocido dentro del sistema del Derecho Laboral la categoría de aviso previo o pre-aviso, requisito formal para comunicar a la otra parte, la decisión de dar por terminada la relación laboral, protegiendo especialmente al trabajador contra el uso arbitrario del despido y, por otra parte, al empleador, cuando es el trabajador quien toma la iniciativa de dar por terminado el vinculo laboral, requiriendo el primero de un tiempo prudencial para garantizar la continuidad de la labor. Se reconoce también, por la doctrina y la legislación, el derecho de accionar contra la decisión administrativa que perjudique el status laboral del trabajador, fundamentalmente ante aquellas decisiones que disuelvan el vínculo laboral.

La legislación laboral cubana, además del contrato admite otras formas de iniciar la relación jurídica laboral: la presunción, la elección y la designación, para estas últimas rigen normas particulares 0 específicas, siéndoles aplicables las 
disposiciones relativas a los contratos de trabajo, con excepción de las cuestiones de modificación y terminación de la relación laboral y la aplicación de medidas disciplinarias.

Distingue, la legislación vigente, las causas que determinan el cese de la relación jurídica laboral, atendiendo a la forma en se formaliza; regulando entre ellas la manifestación de voluntad de las partes, que recoge además del acuerdo de ambas partes, la iniciativa de una de las partes. Se exige para administración y trabajador un término de aviso previo que varía en dependencia del tipo de contrato y del grado de complejidad de la tarea que realiza el trabajador en correspondencia con su escala salarial.

El aviso previo en la legislación cubana va más allá de la tendencia internacional de proteger al trabajador contra el despido injustificado, pues le otorga el derecho de accionar ante la autoridad competente en los casos en que no se cumple el requisito anterior con toda la formalidad legal, obteniendo la correspondiente indemnización; en consecuencia, no sólo protege a la administración otorgándole un tiempo para que pueda encontrar un sustituto del trabajador que le garantice la continuidad de la prestación del servicio o la producción, sino que protege al trabajador contra la posibilidad de que la administración decida retenerlo por un período de tiempo superior al no encontrar un sustituto, puesto que al término del tiempo exigido legalmente para el aviso previo, el trabajador puede considerar disuelto el vínculo que lo une a la entidad, sin perjuicios para él.

El tema adquiere especial relevancia al existir sectores que, dada sus características especiales, resulta necesario establecer para ellos normas específicas, tal es el caso del Ministerio de Salud Pública, encargado de garantizar, como tarea fundamental priorizada por el Estado, la protección de la salud de todos los ciudadanos; en tal sentido "EI MINSAP tiene a su cargo la rectoría metodológica, técnica y científica, en la prestación de los servicios, elabora el Plan Ramal de la Salud Pública y regula el ejercicio de la medicina y de las actividades que le son afines, fijando las condiciones, requisitos $y$ limitaciones de las mismas." 1 Tales funciones se erigen sobre la base de: “...el reconocimiento y garantía del derecho de toda la población a que se atienda y proteja adecuadamente su salud en cualquier lugar del territorio nacional...."

El Ministerio de Salud Pública, al amparo del artículo 65 del Código de Trabajo, que autoriza: "La contratación y otras cuestiones de carácter laboral de los técnicos de la medicina, del personal docente y de la rama artística se efectúa con arreglo a las características de esas actividades y conforme con las medidas dictadas por el organismo respectivo, en coordinación con el Comité Estatal de Trabajo y Seguridad Social", 3 ha promulgado las normas que regulan las relaciones jurídicas laborales con el sector, en tal sentido los procedimientos para iniciar, modificar y terminar la relación laboral con las entidades del sector, distan de las recogidas en la norma sustantiva. 
Los técnicos y profesionales graduados en los centros de enseñanza del Ministerio de Salud Pública, denominados "técnicos propios del sector", una vez graduados formalizan su vínculo con el Ministerio al inscribirse en el Registro de Profesionales y Técnicos, adquiriendo el derecho a ser ubicados en cualquier centro asistencial del país o entidad del Sistema Nacional de Salud. De la misma manera el Ministerio de Salud Pública se reserva el derecho de decidir su ubicación centralizadamente, delegando en las Direcciones Provinciales correspondientes esta facultad, así el personal ubicado conserva el vínculo con el Ministerio y con las Direcciones Provinciales que corresponda; mas, al ser colocados en los centros asistenciales o entidades del sistema, se les formaliza con las mismas la relación jurídica laboral mediante una Carta de Presentación.

La terminación de la relación jurídica laboral con la entidad no entraña el cese del vínculo laboral con la Dirección Provincial respectiva ni con el Ministerio de Salud Pública; el vínculo se disuelve por iniciativa del trabajador, cuando decide solicitar su "baja" del sector y, por tanto, del Registro de Graduados; por iniciativa de la administración, con la aplicación de la medida disciplinaria de separación del sector, al incurrir un técnico propio en violación grave de la disciplina laboral, o cuando se inhabilita de forma permanente a un profesional en el ejercicio de su profesión, por las mismas causas señaladas.

Las normas del Ministerio de Salud Pública son omisas en cuanto al término de aviso previo, le otorgan al Ministro plenas facultades para decidir si aprueba o no las solicitudes de dar por terminado el vínculo con el sector por iniciativa del trabajador, así como el término en que tomará la decisión. Tampoco existe la posibilidad, para el técnico propio del sector, de accionar contra tales decisiones. Tales desregularizaciones provocan un gran descontento entre el personal propio del sector, fundamentalmente en aquellos que deciden terminar su vínculo laboral con el Ministerio para incorporarse a otras actividades, afines 0 no, en otros sectores.

Resulta menester, por tanto, modificar la legislación especial vigente del Ministerio de Salud Pública para atemperarla, en la medida de lo posible, a la legislación sustantiva o a las tendencias actuales del legislador cubano, sin que por ello se menoscabe el derecho de todo ciudadano a que se le garantice la atención a su salud.

Acercamiento a una definición de vínculo laboral. Características y diferencias con la noción de relación jurídica laboral: No es el objeto de nuestro trabajo ofrecer conceptos acabados que, de por sí, requieren de toda una investigación independiente a los efectos de concretar y concentrar todos los conocimientos acumulados a través del desarrollo histórico del Derecho Laboral como rama autónoma del Derecho. No obstante, consideramos necesario acercarnos a una definición de términos tales como relación jurídica laboral, diferenciándolo del vínculo laboral atendiendo a los elementos característicos que distinguen ambos conceptos. Acotamos además que para el presente trabajo nos referiremos a la relación jurídica laboral individual, es decir, a la relación personal o física entre un trabajador y su empleador. 
Existen diversos criterios a la hora de ofrecer una definición de relación jurídica laboral, atendiendo a cuestiones de técnica jurídica y vinculados a problemas sociales; siendo las más frecuentes, en primer lugar, aquellas que consideran que toda relación laboral es, por fuerza, una relación jurídica; un segundo grupo estima que la relación laboral o de trabajo y relación jurídica laboral son cuestiones diferentes. Otros, sin embargo, siguen la tesis contractual civilista que consideraba, inicialmente, a la relación laboral como una forma especial de arrendamiento de servicios, toda vez que la relación laboral no tenía valor por sí misma. Surgen así las teorías del arrendamiento, la de compraventa, la de sociedad y la del mandato.

Numerosos juristas burgueses definen la relación individual de trabajo como la articulada mediante un contrato de trabajo, y que consiste en el intercambio continuado de una prestación de servicios y una remuneración. Esta relación tiene como protagonista al trabajador y al empresario, y en ella confluyen varias fuentes reguladoras que constituyen la base para el ejercicio de diferentes derechos y deberes por parte del trabajador y del empresario. Por otra parte, la mayoría de los Códigos de Trabajo de América Latina asumen como sinónimos la relación de trabajo y relación laboral y equiparan la relación de trabajo al concepto de contrato de trabajo (Chile, Venezuela, Costa Rica, Argentina).

Criterios con los que no estamos de acuerdo, pues si bien es cierto que la relación tiene como protagonistas al trabajador y al empresario (Patrón), estaríamos limitando como única forma de iniciar la relación laboral al contrato de trabajo, otorgándole un carácter eminentemente contractual al concepto, y dejaríamos fuera aquellas relaciones laborales que no se inician ni se formalizan mediante un contrato de trabajo, además de que las relaciones represtación de servicios a cambio de una remuneración no son exclusivas del Derecho Laboral y por tanto no identifica a este tipo de relaciones.

Para la doctrina socialista, representada por la escuela soviética en la época en que el derecho cubano se sovietizo, la relación laboral es aquella que se establece entre el obrero o empleado y la empresa socialista, dentro del ámbito de un colectivo de trabajadores de una empresa u otra organización que se obliga a garantizar el trabajo al obrero o empleado, en correspondencia con su especialidad, calificación o cargo ocupacional, para pagar su trabajo y crear las condiciones necesarias para garantizar la salud y desarrollo de la personalidad del mismo.

En este caso, consideramos que existe la tendencia a identificar el concepto de relación jurídica laboral con el de contrato de trabajo, además de constreñirlo a una exclusiva forma de producción socialista. Parúas Toll entiende como relación jurídica laboral, aquellas relaciones de trabajo entre empleados y empleadores, las cuales, considera, se formalizan y regulan a través de un contrato de trabajo o designación.

Definición ésta bastante generalizadora, se omiten elementos que han de tenerse en cuenta, necesariamente, para diferenciar la relación del vínculo laboral, no obstante reconoce la posibilidad de la existencia de la relación aunque no se haya 
formalizado, al reconocer que la relación jurídica laboral no se inicia sino que se formaliza mediante contrato de trabajo o designación, a la vez que incluye otra forma de formalización de la misma, criterio en que no todos los autores están de acuerdo. A pesar de ello, deja fuera aquellas personas electas para ocupar un cargo o desempeñar determinadas funciones en una entidad laboral, con la cual se establece una relación jurídica laboral independientemente de que esté sujeto a otros procedimientos para su elección o revocación de su mandato.

Otros autores cubanos, recogiendo el criterio que ha asumido la cátedra de Derecho de la Universidad de La Habana, consideran que la relación jurídica laboral "es el vínculo que se establece entre un trabajador y una entidad laboral, según el cual una parte, el trabajador, se obliga, al incorporarse al colectivo de trabajo, a realizar determinado tipo de trabajo subordinándose al orden laboral interno de la entidad, mientras que la otra parte, o sea, la entidad laboral, se obliga a retribuirle su trabajo en correspondencia con su cantidad y calidad, a crearle condiciones de trabajo para su salud y para lograr una alta productividad del trabajo, así como a interesarse por sus necesidades materiales y culturales". 4

Somos del criterio que este concepto al inspirarse en la escuela soviética, reproduce o asume rasgos definitorios del concepto de contrato de trabajo; también asimilan el vínculo laboral como sinónimo de relación jurídica laboral, al reconocer que la relación es el vínculo que se establece entre un trabajador y una entidad laboral, sin hacer distinción entre uno y otro concepto.

Eulalia Viamontes, en un primer momento consideró a las relaciones jurídicas laborales como los vínculos que surgen entre los individuos dentro de un marco específico de la actividad laboral, específicamente dentro de la esfera de la producción y los servicios. Por lo que, concluía, son: “...las relaciones que surgen y mantienes los hombres entre sí (...) en el ámbito laboral, o sea, de la actividad productiva o de la prestación de servicios".

Posteriormente, en un intento de atemperar el concepto a las realidades históricas del Derecho Laboral Cubano, esta autora (recogiendo las tres formas de iniciar la relación jurídica laboral que ella reconoce, por designación, elección y por contrato de trabajo) considera que es "aquella relación social que vincula jurídicamente dentro de la actividad de trabajo, ya sea de producción o de servicios, a un individuo que debe realizar una labor específica dentro de una estructura organizativa dada con arreglo a un orden interno impuesto por esta, con la administración de dicha estructura organizativa la que debe retribuirle por la labor realizada y respeta sus derechos laborales"6

Esta autora, a nuestro juicio, ofrece una definición bastante general, sin considerar otros elementos que deben caracterizar y distinguir ambos conceptos.

Nuestro Código de Trabajo vigente, no ofrece una definición de vínculo laboral, no obstante, del análisis gramatical de la redacción del artículo 5, podemos inferir que se encuentra implícita la diferencia o distinción de ambos conceptos, al definir que 
las relaciones jurídicas laborales "son aquellas que surgen de la vinculación laboral del trabajador con las entidades laborales".

Queda claro para el legislador que en nuestro derecho positivo se reconoce como términos diferentes la relación jurídica laboral y el vínculo laboral, incluso ofrece la relación causal entre ambos, admitiendo que, primeramente, debe existir un vínculo laboral que da origen a la relación jurídica laboral, o dicho de otra manera, no debe existir esa relación si no existe un vínculo laboral que la origine.

En común encontrar en la doctrina referencias a conceptos o definiciones de la relación jurídica laboral, diferenciada de la relación laboral o de trabajo por algunos autores, pero muy pocos la distinguen del vínculo laboral, es así que, en ocasiones, confunden ambos términos o los usan indistintamente dejando implícita la idea de que se trata de dos conceptos diferentes.

Elementos distintivos de la relación jurídica laboral y el vínculo laboral: Nos acercaremos más a una correcta definición si consideramos, aunque brevemente, los elementos característicos de la relación jurídica laboral y del vínculo laboral.

La escuela soviética ha ofrecido tres elementos que deben caracterizar a la relación jurídica laboral:

$\checkmark \quad$ el elemento organizativo laboral, basado en el principio de que la incorporación del trabajador al colectivo de trabajo se realiza en condiciones de subordinación al orden laboral interno de la entidad, comprometiéndose el mismo a realizar un trabajo en determinada especialidad, calificación, ocupación o cargo que forma parte de la actividad general de dicha entidad;

$\checkmark \quad$ el elemento retributivo, o sea, el salario como rasgo inseparable de la relación laboral que permite al trabajador la adquisición de los bienes y el pago de los servicios y constituye la base de su propiedad individual; y

$\checkmark \quad$ el elemento personal, que se expresa en el cumplimiento de las obligaciones laborales, en el derecho al salario, a honores, estímulos, entre otros de carácter personal.

Los elementos de la relación jurídica laboral que ofreció la escuela soviética se atemperaban al momento histórico en que fueron formulados pero no lo están para las nuevas organizaciones empresariales surgidas y que hemos asumido en nuestra economía.

La escuela venezolana asume como elementos constitutivos de la relación laboral:

$\checkmark \quad$ el consentimiento, que consideran ha de ser mutuo,

$\checkmark \quad$ el objeto, y

$\checkmark \quad$ la causa;

Dentro del objeto y la causa incluyen la prestación de servicios, la subordinación y el salario o remuneración. 
En Paraguay se considera la subordinación del trabajador al patrón, como un hecho principal que da lugar al reconocimiento de la existencia de una relación jurídica laboral, no reconociendo el consentimiento como elemento característico como lo hace el legislador venezolano.

En ese sentido, la jurisprudencia Argentina valora la caracterización de la dependencia personal propia del contrato de trabajo como la posibilidad que tiene el empleador de dar órdenes y de sustituir en todo momento la voluntad del trabajador por la suya propia, llamándola subordinación jurídica. No obstante, esas facultades de dirección del empleador deben tener límites legalmente establecidos, pues "coloca a los trabajadores en condición de subordinación, lo cuál no es pura y simplemente como la del derecho común de carácter jurídica simplemente, sino especial por lo compleja ya que generalmente contiene ingredientes económicos, sociales, y técnicos; y además un acentuado grado de colaboración y vocación de estabilidad. La subordinación se proyecta en un triple sentido: técnica, en cuanto el trabajador somete su labor a los procedimientos productivos, planes y objetivos señalados por el empleador; económica, puesto que el trabajador no recibe el producto íntegro de su trabajo y no comparte con el empleador el riesgo de su empresa; y jurídica en tanto debe acatar la dirección y facultades propias del empleador. Sobre esta última cabe recordar que debe existir aún en forma potencial, porque cuanto mayor sea el grado de profesionalismo del trabajador y pueda tomar determinadas decisiones, hasta incluso en la cogestión, menor se presentará la subordinación técnica, pero esa potencialidad latente del empleador siempre estará vigente. Del poder de dirección emana el poder disciplinario, pero se encuentra condicionado."

La jurisprudencia costarricense al interpretar los artículos 4 y 18 de su Código de Trabajo, reconoce como elementos esenciales y básicos, conformadores de una verdadera relación laboral a:

$\checkmark \quad$ la prestación personal de un servicio,

$\checkmark \quad$ la remuneración mediante el pago de un salario, y

$\checkmark \quad$ la subordinación jurídica.

Con relación a este último elemento, jurisprudencial y doctrinalmente se ha establecido que, normalmente, tal subordinación o dependencia es el elemento fundamental para determinar si se está, o no, en presencia de una relación laboral.

Tal criterio es asumido por la escuela chilena, que exige el vínculo de subordinación o dependencia como elemento del cual dependerá determinar si se configura una relación laboral, por cuanto la prestación de servicios y el pago de los mismos con una remuneración determinada pueden estar presentes en otra clase de relaciones jurídicas de naturaleza civil o comercial.

Al considerar como relación laboral, únicamente a la formalizada en virtud del contrato de trabajo, puesto que consideran trabajador a "toda persona natural que preste servicios personales intelectuales o materiales, bajo dependencia o 
subordinación, y en virtud de un contrato de trabajo"9, es así que la jurisprudencia chilena asume como elementos de la relación jurídica laboral los mismos exigidos para el contrato de trabajo en su Código de Trabajo.

Guido Machiavello considera que la subordinación impone deberes a los trabajadores respecto a las facultades discrecionales del empleador, por lo que "jurídicamente se manifiesta en obligaciones conexas y en un modo singular de cumplimiento de la obligación laboral que se extiende en el tiempo". ${ }^{10}$

Por otra parte, esta jurisprudencia chilena ha asumido que el vínculo de subordinación se materializa a través de diversas manifestaciones concretas tales como;

$\checkmark \quad$ la continuidad de servicios prestados en el lugar de la faena,

$\checkmark \quad$ la obligación de asistencia del trabajador,

$\checkmark \quad$ el cumplimiento de un horario de trabajo,

$\checkmark \quad$ la obligación de ceñirse a las órdenes e instrucciones dadas por el empleador, entre otras.

Sin embargo, algunos juristas chilenos no están de acuerdo con lo hasta ahora planteado, pues consideran que al admitir la relación de subordinación como elemento fundamental para distinguir las relaciones laborales de relaciones de otra naturaleza, se dejan desprotegidos otros sectores que requieren protección del derecho laboral como los funcionarios, y trabajadores que ocupan cargos por elección, por ello prefieren denominarla de otra manera: "A ese nuevo tipo de la dependencia jurídica la denominaremos noción funcional de la subordinación, construida, fundamentalmente, sobre los rasgos productivos de la relación entre las partes (...). La construcción de un tipo productivo de la subordinación significa que ésta corresponde a la dirección que un sujeto de derecho, denominado empleador, efectúa de la actividad que coordinadamente ejecuta otro para él, quien se incorpora en forma continuada a la esfera productiva que controla el primero, lo que se manifestará en una serie de indicios vinculados más que a hechos físicos y espaciales (utilización de uniforme, instrucciones, control directo, trabajo en lugar de la empresa), a determinados rasgos de la cooperación mutua entre las partes, tales como: la fijación de la modalidad productiva a ser ejecutada por el trabajador (qué producir, cómo y a qué ritmo), la coordinación informática, la exclusividad como cliente, la propiedad de la infraestructura utilizada, la fijación de un estatuto de sanciones pecuniarias, etc. De este modo, la técnica de indicios propia del tipo de la subordinación se ve enriquecida por la concurrencia de nuevos indicios que responden a la idea de coordinación y producción, produciéndose a fin de cuentas, más que una sustitución de un conjunto por otro, una expansión del sistema utilizado por los órganos aplicadores del derecho"11

La recientemente promulgada "Ley de Contratos de Trabajo de la República Popular China, que entró en vigor el 1 de enero de 2008 y tiene como pilar 
principal la Ley Laboral de 1994, se ha hecho eco de las tendencias doctrinales actuales, otorgándole a la relación laboral un carácter contractual y definiéndola como "una relación de subordinación correspondida por un salario o remuneración"12

De tales posturas pueden observarse nuevos elementos a considerar si aspiramos a diferenciar los conceptos de relación y vínculo laboral, sin incurrir en el error de confundirlos como hasta ahora hemos visto en la redacción de algunos autores. Por ello coincidimos en la existencia de una subordinación o dependencia del trabajador por cuanto al iniciar una relación laboral debe acatar normas, regulaciones y condiciones ya establecidas por el empleador o la legislación vigente, es así que, a nuestro modo de ver, será fundamental a los efectos de determinar si se está en presencia de una relación jurídica laboral o si existe el vínculo laboral aún en ausencia de la primera; siempre y cuando sea analizada en su relación con los elementos espacio, tiempo, jurisdicción y competencia.

El tiempo y el espacio en la relación jurídica laboral y en el vínculo laboral: La palabra tiempo se deriva del latín tempos, ha sido definido, entre sus múltiples acepciones, como la duración de las cosas; época durante la cual vive alguien o sucede algo; cada uno de los actos sucesivos en que se divide la ejecución de algo. Es una de las formas fundamentales de la existencia de la materia existente.

La doctrina reconoce como jornada de trabajo al tiempo durante el cual el trabajador está a disponibilidad del patrón para prestar su trabajo, o el lapso de tiempo durante el cual el trabajador debe estar disponible, jurídicamente, para que el patrón utilice su fuerza de trabajo intelectual o material.

Durante este tiempo de trabajo el empleado prestará su fuerza de trabajo bajo la subordinación a su empleador, y se obliga durante el mismo a darle continuidad a sus servicios prestados o a la producción de bienes, así como a sujetarse al régimen disciplinario existente y a las disposiciones $u$ órdenes del empleador, teniendo derecho a recibir del empleador, los medios de producción, la garantía de las condiciones de seguridad y protección del trabajo, entre otros derechos.

El espacio, del latín spatium, es una de las formas fundamentales de existencia de la materia, entendido como extensión que contiene toda la materia existente. Una de sus acepciones es la capacidad de terreno, sitio o lugar.

Las relaciones de subordinación se materializan en la continuidad de los servicios prestados en el lugar de trabajo, es decir, en la capacidad de terreno, sitio o lugar que ocupa la entidad; o dicho de otro modo, dentro de los límites del espacio de la entidad laboral de que se trate, dentro de su tiempo de trabajo.

No podemos entender solamente como espacio la superficie o terreno que ocupa, en toda su extensión, la entidad laboral, puesto que algunos cargos u ocupaciones tienen como característica su desempeño fuera de los límites físicos de la entidad, como es el caso de chóferes profesionales, mensajeros, carteros, pescadores, recogedores de deshechos sólidos, o aquellos trabajadores que 
ocasionalmente se trasladan a otros lugares en el desempeño de sus deberes funcionales, entre otros ejemplos. Por ello debemos asumir la existencia de un espacio físico, o sea, la extensión de terreno que ocupa la entidad, y el ficticio, o lugar donde el trabajador desempeñe sus funciones fuera de la entidad.

En este espacio físico o ficticio el trabajador o empleado está obligado a cumplir con sus deberes, ciñéndose a las órdenes o instrucciones del empleador, quien, a su vez, se obliga a crear las condiciones necesarias para que el empleado cumpla con su contenido de trabajo; en virtud del nexo que los une, esto es la relación jurídica laboral y el vínculo entre ambos.

Fuera de ese espacio y ese tiempo de trabajo, el trabajador no está sujeto a esa relación de subordinación y, por tanto, no está obligado a cumplir con las órdenes o instrucciones de su empleador. Sin embargo, no deja de ser trabajador de esa entidad, conserva su vínculo con ella, estando el empleador obligado a garantizar los derechos del trabajador, fundamentalmente su derecho a la seguridad social; el trabajador mantiene un vínculo laboral con la entidad generador de derechos para él pero no de obligaciones con respecto a la entidad.

La jurisdicción y la competencia en la relación jurídica laboral y el vínculo laboral: Jurisdicción proviene de la expresión latina juris dictio, que significa decir el Derecho y alude a la función que asume el Estado a través de los jueces y tribunales de administrar la justicia, aplicando al Derecho los casos concretos que se les presentan. Asimismo se hace alusión al conjunto de órganos que cumplen la función competencial.

La administración de justicia se atribuye a un conjunto de funcionarios a los que se confían diversas materias, por lo que se reconocen diferentes clases de jurisdicción y competencias en función de criterios de especialidad jurídica, como la penal, la contenciosa administrativa, la civil y la social. Por otra parte, se diferencian la jurisdicción ordinaria de las especiales, atendiendo al tipo de procesos que conoce la autoridad; conociendo la primera de una generalidad de materias, mientras que en la segunda intervienen en casos específicos.

La jurisdicción puede ser adjetiva, cuando se refiere al modo y a la forma en que se aplica, así como a la autoridad que puede aplicarla; o sustantiva, cuando se decide qué se aplica, como atributo de soberanía, poder, etc.

La competencia es la capacidad concreta que puede ejercer la autoridad, las posibilidades de actuación que se le atribuyen por razón de los asuntos que le están permitidos de un modo específico. Es aptitud, función.

En el plano de las relaciones laborales la jurisdicción es otorgada al empleador o la máxima autoridad de la entidad laboral, quien ejerce su competencia durante el tiempo de trabajo, dentro del espacio físico o ficticio que ocupa la entidad laboral. Fuera de este tiempo del espacio, la autoridad no pierde la jurisdicción que le fuera otorgada, pero no puede ejercer su competencia sobre el trabajador a pesar de la existencia del vínculo laboral que los une, toda vez que el trabajador no se encuentra bajo esa relación de subordinación o sujeción al patrón, generadora de derechos y deberes para ambas partes, sino que es titular exclusivamente de derechos. 
Esta subordinación o dependencia jurídica, por tanto, es creadora de derechos y obligaciones para ambas partes; impone deberes a los empleados con respecto a las facultades discrecionales del empleador, es decir, debe cumplir con sus obligaciones laborales que se extienden en el tiempo. Este tiempo debe entenderse como el tiempo de trabajo, aquel, según la doctrina, durante el cual el trabajador está a disposición del patrón para prestar su trabajo o, el lapso de tiempo durante el cual un trabajador debe estar disponible, jurídicamente, para que el patrón utilice su fuerza de trabajo intelectual o material. La subordinación se materializa en la continuidad de los servicios prestados en el lugar de trabajo, es decir, dentro de los límites o el espacio de la entidad laboral en cuestión (físico o ficticio)

Para el presente trabajo monográfico consideraremos, por tanto, como relación jurídica laboral al nexo que se establece entre empleado y empleador, durante el tiempo de trabajo, dentro del espacio físico o ficticio de un centro de trabajo, en virtud de una relación de subordinación del empleado a la jurisdicción y competencia de la autoridad con la que se tiene el vínculo laboral, generador de derechos y obligaciones para ambas partes.

El trabajador, no obstante, fuera de su centro de trabajo y de su jornada laboral conserva su nexo con la entidad laboral, puede disfrutar de derechos reconocidos en la legislación vigente sin estar sujeto a esa relación de subordinación. Es a este nexo al que llamaremos vínculo laboral, el nexo entre el empleado y el empleador en el tiempo que dure su vida laboral y el espacio dentro y fuera de la entidad laboral, generador de derechos para el empleado, en el que el empleador pude tener jurisdicción aunque no necesariamente, competencia.

El aviso previo y el derecho de acción frente a la terminación del vínculo laboral:Como forma de protección al trabajador contra el despido injustificado y, como garantía de la continuidad de la prestación de servicios o la producción de bienes de la entidad, se ha instituido el aviso previo o preaviso como requisito obligatorio para dar por terminado el contrato de trabajo por voluntad de las partes.

Cabanellas ha sostenido que: "... el preaviso constituye la noticia que una parte da a otra de su propósito de rescindir, vencido el lapso señalado, el contrato de trabajo que los ligaba; presupone siempre la ruptura unilateral del contrato de trabajo, por denuncia que formula una de las partes a la otra; $y$ el hecho de que este aviso previo esté bien o mal dado, se ajuste a los términos de la ley o difiera de ellos, no deja de surtir sus efectos, por cuanto significa una notificación anticipada que una de las partes dirige a la otra sobre su propósito de disolver el contrato." ${ }^{13}$ Agrega el mismo autor que: "El preaviso, es una institución destinada a prevenir situaciones que pueden producirse con la finalización o extinción del vínculo por denuncia de una de las partes". ${ }^{14}$

La jurisprudencia Costarricense se ha pronunciado por: "El preaviso, se inscribe dentro de la buena fe $y$ tiene como finalidad que las partes puedan tomar las 
medidas que estimen convenientes para sus intereses, con motivo de la conclusión de la relación laboral". ${ }^{15}$

En la gran mayoría de los países, los métodos de aplicación nacionales exigen de uno u otro modo la observancia de un período de preaviso. El derecho a un plazo de preaviso es el derecho que se reconoce con más frecuencia a los trabajadores en materia de terminación. Dicho derecho suele estar garantizado en la legislación así como en los convenios colectivos. En muchos de los países en los que se exige un plazo de preaviso antes de que pueda procederse a la terminación de un contrato de trabajo, este requisito sólo se aplica a los contratos de duración indeterminada; se suele considerar que los contratos de duración determinada o por obra terminan, respectivamente, cuando expira el período de trabajo previsto o cuando finaliza la obra en cuestión. En determinados países debe remitirse a las autoridades una copia del preaviso antes de proceder a terminar la relación de trabajo con ciertos trabajadores, y puede incrementarse la duración del mismo en caso de terminación colectiva; en Venezuela, por citar un ejemplo, en el artículo 104 de la Ley Orgánica del Trabajo reconoce que "cuando la relación de trabajo por tiempo indeterminado finalice por despido injustificado o basado en motivos económicos o tecnológicos, el trabajador tendrá derecho a un preaviso"16

En la doctrina se le ha llamado acción "al poder jurídico que tiene el individuo de dirigirse a los órganos de la jurisdicción" ${ }^{\prime 17}$, aunque para muchos juristas ese vocablo tiene en el derecho un significado casi infinito, por ejemplo, "...en derecho penal, acción se opone a la omisión. En derecho comercial, su significado nada tiene que ver con el penal. En el derecho civil se utiliza seguido de nombre propios que caracterizan ciertos tipos de derechos substanciales. En el derecho administrativo denota la gestión de los administrados ante la administración. Esas mismas acepciones han variado, y son distintas en los países del "common law"."18

Sin detenernos en exhaustivos y profundos análisis del tema, como intento de determinar qué entendemos por acción en el derecho laboral, nos referiremos brevemente a algunas definiciones; en el derecho romano, la acción es una potestad jurídica de requerir del tribunal la satisfacción de un crédito o la entrega de una cosa; para otros, involucra el del derecho y la acción: el derecho en movimiento; con la evolución de las concepciones del derecho, juristas argentinos han aceptado como acción al "poder jurídico del individuo de requerir de la jurisdicción la prestación de cuanto es menester para reintegrarle o asegurarle efectivamente, el goce de su derecho violado, resistido o en estado de incertidumbre. La acción es la potestad de obtener la jurisdicción cuanto fuere necesario para la efectividad del derecho del individuo."19 En otras palabras, cuando un individuo se siente objeto de una injusticia, de algo que el considera contrario a su condición de sujeto de derechos, debe acudir ante la autoridad. En 
la doctrina existe consenso en considerar que la acción se comporta, en el estado de derecho, como una petición a la autoridad; esa petición ante la autoridad constituye un poder jurídico del individuo, como medio necesario para obtener la prestación de la jurisdicción, lo cual no puede ser quitado a nadie, por cuanto es prohibida la justicia por propia mano, "es evidente que debe darse a todo sujeto de derecho la facultad de obtenerlo por mano de la autoridad, privarle de una y otra, sería negarle la justicia misma." 20

En la legislación laboral, es usual encontrar regulaciones de la acción como derecho a reclamar contra la terminación del vínculo laboral por iniciativa del empleador o patrón, específicamente, contra el despido, además de reconocerse la acción para solicitar indemnización por invalidez,

En España se regula el término de 20 días para que el trabajador reclame contra el despido, contados a partir de la fecha en que se produce;

\section{TUTELA JURÍDICA DE LA TERMINACIÓN DEL VÍNCULO LABORAL}

El aviso previo y el derecho de acción. Tutela jurídica de la terminación del vínculo laboral: Las primeras normas jurídicas sobre las relaciones laborales las encontramos con el surgimiento de las relaciones de producción capitalista; régimen en el que los obreros se organizaron para luchar por reivindicaciones económicas y ventajas sociales. Primeramente su lucha estuvo dirigida a la duración de la jornada de trabajo, lográndose regulaciones legales a tales efectos; la clase obrera inglesa logró legalizar la jornada de 10 horas, Ley que fue aceptada por la mayoría de los gobiernos continentales. Al lograr esta regulación la clase obrera luchó entonces por el descanso semanal, el nivel de los salarios, la protección de los menores y mujeres, las condiciones de trabajo, etc.

El fundamento del surgimiento, modificación y terminación de la relación jurídica laboral y del vínculo laboral con una entidad, radica en el libre ejercicio de la voluntad de las partes de la misma, aunque es válido decir que la modificación y la terminación de la relación y el vínculo laboral no siempre responde a la voluntad coincidente de ambas partes, sino a situaciones que puede prever la legislación. Teniendo en cuenta que las condiciones de trabajo nunca permanecen intactas respecto al primer día en que se formalizó o se inició el vínculo; la actividad laboral está sujeta a la posibilidad real del cambio, la terminación del vínculo laboral o de las relaciones jurídico laborales no debe considerarse como un hecho negativo, pues puede ser expresión del desarrollo de las relaciones laborales.

Al existir la tendencia, en el plano internacional, de considerar al contrato como principal o única forma de formalizar la relación laboral, las causas que su legislación positiva recoge para dar por terminado el contrato de trabajo son las mismas que la jurisprudencia reconoce para dar por terminada la relación laboral, en tal sentido ilustraremos cómo se comporta en la legislación de otros países: 


\section{- México:}

La Ley Federal del Trabajo contempla más de 15 causas de terminación de la relación de trabajo, entre ellas el mutuo consentimiento, la muerte del trabajador, muerte del patrono, conclusión de la obra contratada, renuncia, despido injustificado (negociado), incapacidad física, jubilación, rescisión, cierre de la empresa, substitución patronal, etc. La rescisión del contrato es una figura del Derecho Civil, es una forma anormal de terminar los contratos, en este caso se asimila por el Derecho Laboral y se constituye en un derecho del patrón, quien podrá rescindir en cualquier momento la relación de trabajo por causa justificada, sin incurrir en responsabilidad cuando el trabajador incumple con el contrato concertado con el patrón, ya sea verbal o por escrito.

\section{- Venezuela:}

En la Ley Orgánica del Trabajo, se reconocen como causas de terminación de la relación de trabajo: "La relación de trabajo puede terminar por despido, retiro, voluntad común de las partes o causa ajena a la voluntad de ambas", ${ }^{21}$ en tal sentido entienden como despido a "la manifestación de voluntad del patrono de poner fin a la relación de trabajo", ${ }^{22}$ en cambio el retiro es "la manifestación de voluntad del trabajador de poner fin a la relación de trabajo". ${ }^{33}$ En cuanto al despido enumeran diversas causas para el despido justificado, injustificado, indirecto, individual o colectivo.

\section{- Costa Rica:}

El Código de Trabajo de Costa Rica, no establece una clasificación de las causas, sino que, además de consignar en su articulado los motivos por los cuales no puede darse por terminada la relación iniciada en virtud de un contrato de trabajo, enumera una serie de supuestos que se corresponden con la observancia de la disciplina laboral, tales como: cuando el trabajador se conduzca durante sus labores en forma abiertamente inmoral, o acuda a la injuria, a la calumnia o a las vías de hecho contra su patrono durante el tiempo que se ejecutan los trabajos, siempre que como consecuencia de ello se altere gravemente la disciplina y se interrumpan las labores; cuando el trabajador, fuera del lugar donde se ejecutan las faenas y en horas que no sean de trabajo, acuda a la injuria, a la calumnia o a las vías de hecho contra su patrono o contra los representantes de éste en la dirección de las labores, siempre que dichos actos no hayan sido provocados y que como consecuencia de ellos se haga imposible la convivencia y armonía para la realización del trabajo; cuando el trabajador cometa algún delito o falta contra la propiedad en perjuicio directo del patrono o cuando cause intencionalmente un daño material en las máquinas, herramientas, materias primas, productos y demás objetos relacionados en forma inmediata e indudable con el trabajo; cuando el trabajador comprometa con su imprudencia o descuido absolutamente 
inexcusable, la seguridad del lugar donde se realizan las labores o la de las personas que allí se encuentren; cuando el trabajador deje de asistir al trabajo sin permiso del patrono o sin causa justificada durante dos días seguidos o dos veces en un mismo mes; cuando el trabajador se niegue de manera manifiesta y reiterada a adoptar las medidas preventivas 0 a seguir los procedimientos indicados para evitar accidentes o enfermedades; o cuando el trabajador se niegue en igual forma a acatar, en perjuicio del patrono, las normas que éste o su representantes en la dirección de los trabajos le indique con claridad para obtener la mayor eficacia y rendimiento en las labores que se están ejecutando, entre otras muchas.

\section{- Chile:}

El Código del Trabajo de Chile establece, en su artículo 159. "El contrato de trabajo terminará en los siguientes casos: 1.- Mutuo acuerdo de las partes. 2.Renuncia del trabajador, dando aviso a su empleador con treinta días de anticipación, a lo menos. 3.- Muerte del trabajador. 4.- Vencimiento del plazo convenido en el contrato. La duración del contrato de plazo fijo no podrá exceder de un año". ${ }^{24}$

Tutela jurídica del aviso previo y el derecho de acción: El Convenio No. 158 de la Organización Internacional del Trabajo, de Protección contra el despido injustificado, recoge, además de las causales del despido, la necesidad de regular un término "razonable" de aviso previo al trabajador, las legislaciones de los diferentes países han establecido, como norma, la regulación del término del aviso previo y la consiguiente indemnización del empleado o trabajador cuando esta formalidad se quebranta.

En Venezuela, se regulan los términos conforme a las reglas siguientes:

“a) Después de un (1) mes de trabajo ininterrumpido, con una semana de anticipación;

b) Después de seis (6) meses de trabajo ininterrumpido, con una quincena de anticipación;

c) Después de un (1) año de trabajo ininterrumpido, con un (1) mes de anticipación; d) Después de cinco (5) años de trabajo ininterrumpido, con dos (2) meses de anticipación; $y$

e) Después de diez (10) años de trabajo ininterrumpido, con tres (3) meses de anticipación." 25

Cuando la relación de trabajo por tiempo indeterminado termine por retiro voluntario del trabajador, sin que haya causa legal que lo justifique, éste deberá dar al patrono un preaviso conforme a las reglas siguientes:

“a) Después de un (1) mes de trabajo ininterrumpido, con una semana de anticipación; 
b) Después de seis (6) meses de trabajo ininterrumpido, con una quincena de anticipación; $y$

c) Después de un (1) año de trabajo ininterrumpido, con un (1) mes de anticipación;"”26

En Chile, en virtud de la Ley 19.378 "Estatuto de Atención Primaria de Salud Municipal", en su artículo 48, en el sistema de salud primaria municipal, el empleador no está obligado a dar aviso anticipado de la terminación de los servicios, ni a otorgar finiquito, resultando suficiente para ello la resolución corporativa mediante la cual se pone término al contrato. "En el sistema de salud municipal, el empleador no está obligado a dar aviso anticipado de 30 días del término del contrato como tampoco a pagar indemnización por falta de ese aviso. ${ }^{127}$

La ley 19.378, en ninguna de sus disposiciones, contempla formalidad alguna para los efectos de la terminación de los servicios de los funcionarios afectos a dicho cuerpo legal, de manera que el empleador no se encuentra obligado ni a dar aviso anticipado del término del contrato ni a otorgar finiquito. Lo anterior implica que los funcionarios de salud primaria municipal, sujetos a contrato a plazo fijo, tampoco tienen derecho al pago de la indemnización por años de servicio

En Argentina, el contrato de trabajo no podrá ser disuelto por voluntad de una de las partes, sin previo aviso, o en su defecto, indemnización además de la que corresponda al trabajador por su antigüedad en el empleo, cuando el contrato se disuelva por voluntad del empleador. El preaviso, cuando las partes no lo fijen en un término mayor, deberá darse con la anticipación siguiente:

“a) por el trabajador, de QUINCE (15) días;

b) por el empleador, de QUINCE (15) días cuando el trabajador se encontrare en período de prueba; de UN (1) mes cuando el trabajador tuviese una antigüedad en el empleo que no exceda de CINCO (5) años y de DOS (2) meses cuando fuere superior." 28

Tratamiento de la terminación de la relación jurídica laboral y el vínculo laboral en la legislación laboral cubana. Términos de aviso previo y derecho de acción.

- Tratamiento de la terminación de la relación jurídica laboral y el vínculo laboral en la legislación laboral cubana: Según el resultado de nuestra revisión bibliográfica, se ha considerado como primera manifestación de legislación laboral en Cuba la Ley del Patronato, Ley del 13 de febrero de 1880, la que tuvo como antecedente la proclama leída por Carlos Manuel de Céspedes el 10 de octubre de 1868, refrendada posteriormente en la Constitución de Guáimaro; otros ven en el Reglamento de honrados obreros, y bomberos de 1867 
un preámbulo de las normas de Derecho Laboral, donde se advierten elementos de una relación laboral, reconociéndose la existencia de los obreros. Pero la realidad es que, desde que se organiza la clase obrera cubana para demandar sus mejoras en el siglo XIX, a pesar de los congresos de 1887 y 1892 con las consecuentes huelgas generales en pos de la regulación de la jornada de trabajo de 8 horas, el reconocimiento de los derechos civiles de los miembros de los gremios de la raza negra, entre otros reclamos, no se contaba con una legislación especial para regular relaciones entre patronos y obreros. Todo lo relativo a las relaciones individuales entre patronos y obreros se establecieron en el Código Civil de 1889, denegándole a la relación laboral el valor por sí misma, al considerarla como un arrendamiento de servicios, en cambio a las relaciones entre comerciantes con sus auxiliares, así como la de los capitanes y sus tripulaciones se regulaban en el Código de Comercio de 1885, que dedicó algunas normas a las causales de despido.

No fue hasta el año 1909 en que se comenzaron a promulgar legislaciones laborales, con la primicia de la Ley Orgánica del Poder Ejecutivo, que estableció, entre otros aspectos, la competencia de los asuntos laborales al Secretario de Agricultura, Comercio y Trabajo. Le siguió la conocida "Ley Arteaga", de ese mismo año, que prohibía la emisión en pago de jornales, sueldos o cualquier otra obligación, de vales, chapas, fichas metálicas o de cualquier otra clase que tuvieran el carácter de signos representativos de la moneda. Se sucedieron numerosas legislaciones que refrendaban las conquistas progresivas de la clase obrera cubana, como la Ley del cierre de los Establecimientos Comerciales, promulgada en 1910, que dispuso la terminación de la jornada de trabajo a las 6:00 p.m. de lunes a viernes y los sábados a las 10:00 p.m. de los establecimientos de comercio y talleres situados en los barrios urbanos de los municipios de primera y segunda clase, prohibía además los trabajos en los días festivos y domingos, con excepción de los hoteles, restaurantes, cafés, entre otros. Ese mismo año se promulgó la Ley del Salario Mínimo de los obreros del Estado, la provincia o el municipio; en 1916 la Ley de los Accidentes de Trabajo; la Ley que admitía a las mujeres como trabajadoras en los comercios de tiendas de ropas femeninas, así como su admisión al trabajo en las taquillas de los cines y teatros.

Después de la caída de Machado, en 1933, fue prolífero en cuanto a legislación laboral, promulgándose así el Decreto 2142 de 15 de octubre de 1933, que creó la Secretaría del Trabajo, independizándose así de la Secretaría de Agricultura y Comercio, el Decreto 2355 de 26 de octubre de de ese año determinó la jurisdicción y competencia de la nueva Secretaría del Trabajo, a la que se atribuyeron las funciones relativas a las relaciones de trabajo, salario, trabajo de menores y mujeres; la seguridad del trabajo, la higiene y la seguridad laboral de los trabajadores, horarios obligados de cierre de establecimientos comerciales, el descanso retribuido obligatorio, paros, huelgas, entre otras facultades; el Decreto 2689 de 17 de noviembre de 1933 que derogó la Ley del 6 de diciembre de 1939 que había modificado la Ley del 23 de junio de 1909 o Ley Arteaga; la Ley 91 de 16 de abril de 1935 conocida como Ley Orgánica de la Secretaría del Trabajo, que estableció la estructura y reglas funcionales de la misma; la Ley 191 de 28 de 
mayo de 1935, la cual reglamentó el funcionamiento de las agencias de empleo o colocaciones; el Decreto 1693 de fecha 19 de septiembre de 1933, estableció la extensión máxima de la jornada laboral en 8 horas cada día, es decir, 48 semanales; el Decreto 2583 Ley Provisional de Nacionalización del Trabajo; el Decreto-Ley No. 3 de 6 de febrero de 1934, reguló las huelgas de patronos y obreros; el Decreto 2687 o Ley de Accidentes del Trabajo; Decreto-Ley 781 de diciembre de 1934 sobre el empleo de las mujeres antes y después del parto.

Dentro de esta prolífera legislación resulta de suma importancia el Decreto-Ley 276 de enero de 1934, que estableció que no podía separarse de su empelo o cargo a ningún trabajador sin motivo justificado y argumentado en un debido expediente laboral, por cuanto por primera vez se trató de proteger al trabajador de las arbitrariedades de los empleadores. Se reguló además la forma en que debían sustanciarse dichos expedientes de despido, responsabilizando civilmente a los patronos de los perjuicios causados por despidos sin justa causa.

Otras legislaciones fueron: el Decreto-Ley 450 de agosto de 1934, que estableció el descanso dominical obligatorio; la Ley 40 del 25 de marzo de 1935, que fijó el descanso retribuido de todos los trabajadores; 13 de abril de 1938 se dictó el Decreto No. 798, sobre los contratos de trabajo, estipulando que los mismos debían contener, entre otras cláusulas, las relativas a la terminación y rescisión del contrato de trabajo, siendo la primera vez que se regulara el procedimiento para la terminación de la relación jurídica laboral para todos los trabajadores. Este Decreto se utilizó aún en los primeros momentos del triunfo de la Revolución de enero de 1959.

El triunfo revolucionario incentivó una gran actividad legisladora, se prohibió el despido, se reguló la seguridad social, la protección e higiene del trabajo, los convenios colectivos de trabajo, la remuneración con arreglo al trabajo, la vinculación del trabajo, la maternidad de la trabajadora, la capacitación técnica de los trabajadores, entre otras regulaciones importantes para la clase obrera cubana.

En agosto de 1980 se promulgó el Decreto No. 73, estableciendo el sistema de contratación directa de la fuerza de trabajo que hasta esa fecha se había mantenido centralizada, siendo el Decreto Ley 40 de 16 de octubre de 1980, el que instituyó al contrato de trabajo como instrumento regulador del proceso de descentralización de la política de empleo.

El 28 de diciembre de 1984 se puso en vigor la Ley 49 Código de Trabajo, donde se regula de manera diferenciada la terminación de la relación jurídica laboral según la forma en que se inicia o formaliza la misma.

La mayoría de los autores cubanos coinciden en reconocer, como formas de iniciar la relación jurídica laboral las consignadas en el artículo 5 del Código de Trabajo: el contrato de trabajo, la designación y la elección; pero lo cierto es que en el tercer párrafo del artículo 28, de la misma norma se regula que "cuando el contrato de trabajo no se formaliza por escrito la relación laboral se presume por 
el hecho de estar el trabajador ejecutando una labor, con conocimiento y sin oposición de la administración de la entidad laboral"29.

De esta misma manera quedó recogido en el artículo 34 de la Resolución 51 de 12 de diciembre de 1988, del extinto Comité Estatal de Trabajo y Seguridad Social, "Reglamento para la Aplicación de la Política de Empleo", aunque en la Resolución No. 8 de 1 de marzo de 2005, del Ministerio de Trabajo y Seguridad Social, "Reglamento General sobre Relaciones Laborales", que deroga la anterior, se omite la referencia a la presunción.

Así el Código de Trabajo, para las relaciones que se formalizan en virtud de un contrato de trabajo, establece como causas de su terminación y por consiguiente de la relación laboral y el vínculo laboral, por cuanto la terminación del contrato de trabajo deviene en acto que disuelve el vínculo laboral formalizado en virtud del mismo, las siguientes:

$\checkmark \quad$ acuerdo de las partes,

$\checkmark \quad$ iniciativa de alguna de las partes,

$\checkmark \quad$ llamado del trabajador para el cumplimiento del servicio militar activo,

$\checkmark \quad$ vencimiento del término fijado, en el caso de los contratos por tiempo determinado.

$\checkmark \quad$ ejecución del trabajo objeto del contrato, cuando se ha concertado a ese fin, $\checkmark \quad$ jubilación del trabajador

$\checkmark \quad$ fallecimiento del trabajador, y

$\checkmark \quad$ extinción de la entidad laboral, cuando no exista la subrogación por cualquier otra.

Estas mismas causales las recoge la Resolución No. 51 de 1988, en tanto la vigente Resolución $\mathbf{8}$ de $\mathbf{2 0 0 5}$ del Ministerio de Trabajo y Seguridad Social, recoge como causas generales de terminación del contrato a:

$\checkmark \quad$ acuerdo de las partes,

$\checkmark \quad$ iniciativa de alguna de las partes,

$\checkmark \quad$ jubilación del trabajador

$\checkmark \quad$ fallecimiento del trabajador, y

$\checkmark \quad$ extinción de la entidad laboral, cuando no exista la subrogación por cualquier otra.

En la norma mencionada se hace la distinción para la relación establecida mediante el contrato de trabajo de aprendizaje, estableciendo como causales de terminación, además de la iniciativa de alguna de las partes:

$\checkmark \quad$ el cumplimiento del término o de los objetivos del curso, y

$\checkmark \quad$ la movilización para el cumplimiento del Servicio Militar Activo. 
En su momento la Resolución 51 de 1988 del extinto Comité Estatal de Trabajo y Seguridad Social, reguló para este tipo de contratos, las ya mencionadas y las causas siguientes:

$\checkmark \quad$ ausencias injustificadas del trabajador por periodos superiores a los permisibles, de acuerdo con los planes y programas de estudios del curso.

En el caso de la iniciativa de las partes, la misma se aceptaba si era dentro los dos primeros meses del curso.

Cuando la terminación del vínculo con la entidad, en el caso de las relaciones formalizadas en virtud de un contrato de trabajo, se debe a la iniciativa del trabajador, nuestra legislación no recoge las razones que este puede invocar, de lo que se infiere, por tanto, que el trabajador pueda invocar razones de cualquier índole 0 , incluso, ninguna.

Si corresponde la iniciativa de dar por terminada la relación jurídica laboral con la entidad a la administración, ha de ser, según el Código de Trabajo, por las causas siguientes:

$\checkmark \quad$ ineptitud del trabajador para realizar un trabajo, debidamente demostrada,

$\checkmark \quad$ falta de idoneidad del trabajador para el desempeño de la ocupación o cargo asignado, cuando se trata del incumplimiento de condiciones específicamente establecidas en el contrato,

$\checkmark \quad$ declaración de disponibilidad del trabajador, siempre que no exista otro trabajo que pueda realizar o que existiendo no sea aceptado por él,

$\checkmark \quad$ invalidez parcial del trabajador, cuando se hayan agotado las posibilidades para su ubicación en la entidad laboral,

$\checkmark \quad$ separación definitiva del trabajador por violar la disciplina laboral,

$\checkmark \quad$ sanción de privación de libertad por sentencia firme o medida se seguridad, en ambos casos, cuando exceda de seis meses,

$\checkmark \quad$ cumplimiento del plazo de la licencia no retribuida para el cuidado de los hijos, sin que la trabajadora se haya reintegrado al trabajo,

$\checkmark \quad$ sanción de privación de libertad por sentencia firme, en los casos de los contratos por tiempo determinado o para la ejecución de un trabajo u obra.

La Resolución 51 de 1988 añadió para los contratos de trabajo en condiciones especiales de aprendizaje:

$\checkmark \quad$ la ineptitud del sujeto para capacitarse;

$\checkmark \quad$ falta de idoneidad si esta se exige para cubrir el cargo;

$\checkmark \quad$ aplicación de la medida disciplinaria de separación del curso;

$\checkmark \quad$ extinción de la entidad laboral, cuando no exista la subrogación por cualquier otra; $y$

$\checkmark \quad$ ausencias que por cualquier causa afecten el rendimiento docente normal. 
Por su parte, la Resolución No. 8 de 2005 del Ministerio de Trabajo y Seguridad Social, establece causas más específicas al señalar para los contratos de trabajo por tiempo determinado o para la ejecución de un trabajo u obra que exceda de seis meses, antes de concluir el término pactado, la administración puede fundamentar las causas:

$\checkmark \quad$ pérdida de idoneidad demostrada del trabajador para el desempeño de la ocupación o cargo como consecuencia de no haber mantenido los requisitos de aptitud; el incumplimiento de normas de conducta general o específica o; en su caso, de determinadas características personales, cuando así lo establece la ley;

$\checkmark \quad$ incorporación del trabajador al cual se encontraba sustituyendo;

$\checkmark \quad$ amortización de la plaza que ocupaba en sustitución del trabajador ausente, antes de la incorporación del mismo;

$\checkmark \quad$ aplicación al trabajador de la medida de separación definitiva de la entidad, o del sector o actividad, cuando proceda, por la inobservancia de las normas de disciplina establecidas en la ley y en los reglamentos disciplinarios internos;

$\checkmark \quad$ incumplimiento del trabajador de las obligaciones contraídas en el contrato de trabajo;

$\checkmark \quad$ cumplimiento del plazo de la licencia no retribuida o en su caso del término del derecho a la prestación social para el cuidado de hijos, sin que la trabajadora o el trabajador se haya reintegrado al trabajo;

$\checkmark \quad$ sanción de privación de libertad por sentencia firme, en los casos de contrato por tiempo determinado, o para la ejecución de un trabajo u obra, y a domicilio de carácter temporal;

$\checkmark \quad$ falta de abastecimiento técnico material que impide cumplir la labor pactada; y

$\checkmark \quad$ cumplimiento de la labor pactada.

En el caso de los contratos de aprendizaje se modifica la redacción de lo recogido en la Resolución 51 de 1988, es así que en el caso de la falta de idoneidad de la persona si esta era exigida para el cargo, quedaría como: falta de idoneidad de la persona; sin especificar si se trata de la idoneidad para el cargo que ocupa o a qué idoneidad se refiere, situación que bien pudiera ser peligrosa a los efectos de dejar en estado de indefensión a un trabajador al que arbitrariamente se le comunica la terminación del contrato con la consecuente terminación del vínculo con la entidad

Aunque las relaciones laborales iniciadas en virtud de la elección están regidas por la legislación específica, el Código de Trabajo dispone que, al igual que a las relaciones iniciadas por designación, le son aplicables las disposiciones relativas a los contratos de trabajo por tiempo indeterminado, con excepción de las cuestiones de modificación y terminación de la relación laboral y la aplicación de medidas disciplinarias. No obstante, establece en el artículo 63 que la relación laboral termina: 
$\checkmark \quad$ al expirar el período por el cual fue electa;

$\checkmark \quad$ por renuncia aceptada;

$\checkmark \quad$ sustitución;

$\checkmark \quad$ incapacidad física o intelectual que le impida el ejercicio de sus funciones;

$\checkmark \quad$ jubilación;

$\checkmark \quad$ revocación del mandato;

$\checkmark \quad$ fallecimiento; y

$\checkmark \quad$ otra causa justificada

La Ley 82 de los Tribunales Populares, establece en el artículo 66 las causas del cese en el ejercicio de la función jurisdiccional de los jueces, adaptándose a lo dispuesto por el Código de Trabajo, aunque no incluye la sustitución como causa, sino "por pasar a desempeñar a otras funciones", 30 además de hacer la aclaración que la expiración del término sólo es para los jueces legos, quienes son electos por un período determinado. La causa aducida como la refleja la Ley 82 , es la misma que se reconoce para los fiscales electos y designados. Por su parte la Ley 83 De la Fiscalía General de la República, no reconoce la expiración del período para el cual fue electo el fiscal, cuestión lógica si se considera que el cargo de Fiscal General de la República, así como los de Vicefiscales Generales, únicos que se ocupan por elección, no constituyen un mandato por un tiempo determinado, y añade como causal "el hecho de ser sancionados penalmente mientras no hayan obtenido su rehabilitación y siempre que el delito cometido no sea de los que hacen desmerecer en el concepto público." 31

La regulación de la relación laboral de los trabajadores designados, bien pudiera tener de antecedente a la Ley de los Cargos Públicos de 12 de agosto de 1869, en la Constitución de 1940 se reconocía la llamada "carrera judicial", los jueces o magistrados alcanzaban plazas únicamente mediante los ejercicios de concurso y oposición, en cambio, los funcionarios del ministerio fiscal eran inamovibles, excepto el Fiscal del Tribunal Supremo, quien era nombrado y removido libremente por el Presidente de la República. Al triunfar la Revolución en enero de 1959, dentro de las reformas constitucionales llevadas a cabo, se suspendió la vigencia de los preceptos constitucionales que establecían la inamovilidad de funcionarios judiciales y fiscales. Actualmente, nuestra Ley sustantiva recoge como causas generales de terminación de la relación laboral iniciada en virtud de la designación:

\footnotetext{
$\checkmark \quad$ renuncia del designado;

$\checkmark \quad$ remoción;

$\checkmark$ democión;
} 
$\checkmark \quad$ jubilación;

$\checkmark \quad$ fallecimiento; y

$\checkmark \quad$ otras causas justificadas

El Decreto-Ley No. 197 de fecha 15 de octubre de 1999, modificado en dos ocasiones, por el Decreto ley No. 236 de 7 de octubre de 2004 y el Decreto Ley No. 251 de 1 de agosto de 2007; "Sobre las Relaciones Laborales del Personal Designado para Ocupar Cargos de Dirigentes y Funcionarios", establece como causas de terminación de la relación laboral formalizada por nombramiento las siguientes:

$\checkmark \quad$ declaración de disponibilidad del trabajador por amortización de la plaza que ocupaba, siempre que no exista reubicación laboral o existiendo, no sea aceptada por él;

$\checkmark \quad$ separación definitiva por medida disciplinaria o por la pérdida de los requisitos o condiciones de prestigio y reconocimiento social, así como el comportamiento laboral y personal ético;

$\checkmark \quad$ invalidez parcial acreditada por peritaje médico, cuando no acepte injustificadamente las propuestas de reubicación laboral;

$\checkmark \quad$ sanción de privación de libertad por sentencia firme o medida de seguridad, en ambos casos, cuando excedan de seis meses;

$\checkmark \quad$ renuncia;

$\checkmark \quad$ vencimiento del término del nombramiento provisional, cuando no tenga derecho a regresar al cargo anterior;

$\checkmark \quad$ vencimiento del plazo de licencia no retribuida para el cuidado de los hijos, sin que la trabajadora se haya reintegrado al trabajo;

$\checkmark \quad$ extinción de la entidad laboral; cuando no exista otra que se subrogue en su lugar;

$\checkmark \quad$ jubilación;

$\checkmark \quad$ fallecimiento

En cambio, el Decreto-Ley No. 196 de 15 de octubre de 1999, "Sistema de Trabajo con los Cuadros del Estado y del Gobierno", igualmente modificado por los Decretos-Leyes 236 y 251, ya mencionados, regula como causas de movimientos que determinan el cese de la relación laboral:

$\checkmark \quad$ separación definitiva de la entidad o del sector o actividad, por incurrir en delito, faltas, negligencia, indisciplina o incumplimiento de deberes establecidos $u$ otras causas imputables al mismo, que son sancionables y que ocasionan afectación de su prestigio y autoridad, por lo que determinan a salida del sistema de cuadros del organismo, entidad u organización, o del sector o actividad de que se trate, o del Sistema de Cuadros del Estado, según la gravedad de los hechos cometidos; 
$\checkmark \quad$ revocación para el caso de los cuadros electos, según se establece en la legislación correspondiente;

$\checkmark \quad$ sustitución por pérdida de alguno o algunos de los requisitos exigidos por la ley para desempeñar el cargo que ostenta, o por haber perdido alguna o algunas de las condiciones esenciales para desempeñarse como cuadro del Estado y del Gobierno, en virtud de las cuales le fue reconocida la condición de tal y ocupar el cargo del que es sustituido

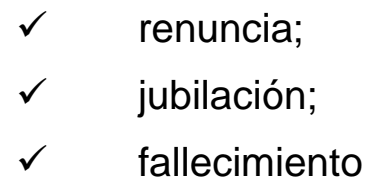

En los cuerpos legales ya analizados no se hace alusión directa a la terminación del vínculo laboral, más, dejan implícito el cese del mismo al dar por terminada la relación jurídica laboral, sin embargo, es curioso que una norma específica para un grupo determinado de trabajadores en circunstancias específicas, se refieran expresamente a la terminación del vínculo laboral, nos referimos a la Resolución 6 del 18 de agosto de 1994, del Ministerio de Trabajo y Seguridad Social "Reglamento para el tratamiento laboral y salarial aplicables a los trabajadores disponibles", que entró en vigor el 1 de septiembre de 1994 y estuvo vigente hasta que fue derogada expresamente por la Resolución 8 de 2005 del mismo Ministerio.

El precitado Reglamento, aplicable a los trabajadores contratados por tiempo indeterminado, designados o electos para ocupar un cargo, y a los contratados por tiempo determinado para cumplir el servicio social, regulaba que los trabajadores disponibles terminarían su vínculo laboral con la entidad cuando se le agotara el período con derecho al pago de la garantía salarial y no se hubieran reubicado a pesar de las gestiones realizadas por la administración. También recogía la "baja definitiva" cuando el trabajador disponible no aceptara injustificadamente la oferta de reubicación, de incorporación a cursos, o abandonará o no aprobara el curso sin justificación.

Las causas de terminación a que hemos hecho alusión, son consideradas por la mayoría de los países como causas de terminación del contrato de trabajo, fundamentalmente aquellos que reconocen solamente el contrato como vía de formalización de la relación laboral, las mismas se han clasificado en nuestro país, atendiendo a tres elementos:

$\checkmark \quad$ por manifestación de la voluntad de las partes: en este grupo se encuentra el acuerdo de ambas partes, en virtud del cual "ambas partes coinciden en que no es necesario continuar la relación laboral, y por ende, procede romper este vínculo formalizado por el contrato de trabajo. Este acuerdo mutuo no significa que las dos partes, simultáneamente, manifiesten el propósito de terminar el contrato, sino que la iniciativa parte de uno de los sujetos y no encontró oposición alguna en el otro. Esto tiene una notable consecuencia jurídica: no se requiere por tanto, de 
pre-aviso ..."; ${ }^{32}$ corresponde a este grupo la iniciativa de una de las partes, en las que se incluyen la iniciativa del trabajador; la iniciativa de la administración; el vencimiento del término fijado, en el caso de los contratos de trabajo por tiempo determinado, ya que la fecha de terminación del mismo fue preestablecida de común acuerdo por ambas partes o por una de ellas; y la ejecución del trabajo objeto del contrato cuando se ha concertado a ese fin. Para los trabajadores designados o electos en este grupo se ubicaría la renuncia aceptada como acuerdo mutuo entre las partes; la revocación del mandato como iniciativa de una de las partes, para los electos; y la democión y remoción para los designados.

$\checkmark \quad$ por caso fortuito: en este grupo puede incluirse el fallecimiento del trabajador, dado a que "constituye un hecho que se escapa de la determinación de las partes (...) y que el día de su ocurrencia se produce en un momento que no puede ser previsto...."33

$\checkmark \quad$ por fuerza mayor: incluimos la extinción de la entidad laboral cuando no exista la subrogación por cualquier otra, así como la jubilación del trabajador, causa que "pudiera decirse que está determinada por la voluntad del trabajador quien desea terminar su vida laboral luego de haber cumplido con los dos requisitos (años de edad y servicios)-, o por la voluntad de la administración -en el caso de trabajadores que han cumplido sus requisitos para jubilarse por edad, pero continúan trabajando por 5 años más con malos resultados laborales y que su administración tiene la facultad de tramitarle su pensión por edad. Sin embargo, existen otros casos en los que el trabajador se jubila por invalidez total como resultado de la pérdida completa de su capacidad laboral por padecer una enfermedad común o profesional o haber sufrido un accidente común o de trabajo, lo cual se escapa de la voluntad del trabajador. Por ello la jubilación se afilia más a la causal de fuerza mayor...."34

Como bien hemos visto, en nuestro país la regulación de la terminación del vínculo laboral se regula indistintamente de acuerdo a la forma en que el mismo se inicia, siendo preferencia del legislador referirse a la terminación de la relación jurídica laboral. A pesar de esto existen causas generales o comunes, como bien pueden ser:

$\checkmark \quad$ Por voluntad de las partes

$\checkmark \quad$ Por caso fortuito

$\checkmark \quad$ Por fuerza mayor

El aviso previo y el derecho de acción en la legislación laboral vigente: EI trabajador no necesita una razón o fundamento legal para dar por terminado su vínculo laboral con la entidad, no obstante, se le exige la comunicación por escrito a la administración en un término que varía según el tipo de contrato concertado. El término de aviso previo se instituye con el fin de proteger la continuidad de la prestación del servicio o la producción, permitiéndole a la 
administración encontrar un sustituto para ese trabajador. A ello obedecen los distintos términos, que aumentan según el grado de complejidad de la tarea que realiza el trabajador.

El Código de Trabajo en su artículo 49, regula la obligatoriedad del aviso previo y la formalidad escrita, estableciendo, en los artículos siguientes, los términos, atendiendo al tipo de contrato concertado y la escala salarial del trabajador.

En el supuesto de la iniciativa del trabajador se exigen para los contratos por tiempo determinado:

$\checkmark \quad$ quince días para los obreros, trabajadores de servicio o administrativos que desempeñen ocupaciones comprendidas en los grupos I y II de la escala salarial;

$\checkmark \quad$ dos meses para los obreros, trabajadores de servicio o administrativos que desempeñen ocupaciones comprendidas en los grupos III, IV y $\mathrm{V}$ de la escala salarial;

$\checkmark \quad$ tres meses para los obreros, trabajadores de servicio o administrativos que desempeñen ocupaciones comprendidas en los grupos VI, VII, VIII y IX de la escala salarial;

$\checkmark \quad$ cuatro meses para los trabajadores que ocupen cargos que exijan, como requisito, un título de nivel superior.

Para los contratos por tiempo determinado o para la ejecución de un trabajo u obra, el término de aviso previo es de quince días. Términos que igualmente reprodujo la Resolución 51 de 1988 y actualmente regula la Resolución 8 de 2005, añadiendo los términos de treinta días para los contratos a domicilio de carácter permanente y siete días para los contratos de aprendizaje y a domicilio con carácter temporal.

La supracitada norma introduce la excepción para las provincias de Ciudad de La Habana y La Habana, facultando al Ministerio de Trabajo y Seguridad Social a establecer otros términos de aviso previo para estas provincias y para otros sectores, ramas o actividades, en atención a la índole de la labor que se realiza o para asegurar el cumplimiento de obligaciones legales contraídas por el trabajador.

En cuanto al término de aviso previo de la administración, las normas ya señaladas coinciden en:

$\checkmark \quad$ treinta días para las causales de ineptitud, falta de idoneidad, invalidez parcial o declaración de disponibilidad;

$\checkmark \quad$ quince días para el contrato de trabajo por tiempo determinado o para la ejecución de un trabajo u obra antes del plazo previsto.

Añade la Resolución 8 de 2005:

$\checkmark \quad$ siete días para contratos a domicilio de carácter temporal antes del cumplimiento del término. 
La acción procesal "constituye, según su concepto clásico, una petición contra el Estado para obtener una situación favorable", ${ }^{35}$ el Tribunal Supremo de Justicia, en su sentencia No. 141 de fecha 12 de diciembre de 1946 y otras posteriores, declaró con respecto a la definición de la acción procesal, que era la “...forma específica de solicitar la revocación de lo ya resuelto, los que requieren en sus diferentes casos y situaciones una tramitación que es la ley la llamada a regular...."36

En el plano de las relaciones jurídicas laborales, el derecho de acción contra las decisiones administrativas se materializa en los recursos que la propia ley concede al trabajador para solicitar la modificación o revocación de una decisión o situación de hecho que considere le vulnere sus derechos, como es el caso de la acción para reclamar ante el Órgano de Justicia Laboral de Base su inconformidad con la aplicación de medidas disciplinarias, violaciones del régimen de seguridad social a corto plazo, del régimen salarial, y reclamaciones de derechos, como también pueden acudir al Tribunal Municipal Popular correspondiente cuando no se encuentran conforme con el fallo del Órgano de Justicia Laboral de Base en los casos de aplicación de medidas disciplinarias iniciales consistentes en traslado a otra plaza de menor remuneración o calificación, o de condiciones laborales distintas, con pérdida de la que ocupaba, la de separación definitiva de la entidad, y en materia de derechos laborales.

La acción procesal del personal electo o designado es regulada por las normas del derecho administrativo.

Las normas no prevén de una marera casuística la acción para reclamar el incumplimiento de los términos de aviso previo de dar por terminado el vínculo laboral al trabajador, por parte de la administración, pues asumen que, para aquellos trabajares que formalizan su relación jurídica laboral mediante un contrato de trabajo, el mismo se termina, y por consecuencia la relación laboral, cuando transcurre el término de aviso previo. A pesar de esto, el trabajador se reserva el derecho de acudir al Órgano de Justicia Laboral de Base a efectuar su reclamación de derechos ante la posibilidad de que sea retenido a los efectos de esperar que la administración encuentre sustituto.

\section{El despido. Su regulación jurídica actual.}

El despido como acción unilateral del empleador en Cuba no se regula abiertamente, no obstante, partiendo del criterio de clasificación entre libre despido, o sea, cuando el empleador es libre de despedir al trabajador sin expresión de causa, aunque no es aceptado por la doctrina; y el despido regulado, instituido como derecho del empleador para despedir al trabajador ciñéndose a una serie de regulaciones legales, podemos encontrar en nuestra legislación vigente algunas regulaciones de esta última modalidad, como sería el caso de la terminación del vínculo laboral en virtud de la iniciativa de la administración ante violaciones de la disciplina laboral y por la pérdida de los requisitos de idoneidad demostrada, fundamentalmente. Sin embargo, de 
naturaleza distinta sería la declaración de disponibilidad regulada en la legislación actual como causal de despido.

La Resolución no. 35 de fecha 7 de octubre de 2010 puso en vigor el "Reglamento sobre el tratamiento laboral y salarial aplicable a los trabajadores disponibles e interruptos", partiendo de la declaración de "disponibles" a aquellos trabajadores cuya plaza se amortice, es decir, se cancele o desactive la plaza "que hasta ese momento venía siendo ocupada con carácter permanente" 37 , estableciendo para estos trabajadores una garantía salarial equivalente al ciento por ciento de su salario básico en correspondencia con los años de servicio, de la siguiente manera:

$\checkmark \quad$ hasta un mes para los trabajadores que acrediten de 10 a 19 años de servicio,

$\checkmark \quad$ hasta dos meses para los que acrediten de 20 a 25 años,

$\checkmark \quad$ hasta tres meses para los que acrediten de 26 a 30 años, y

$\checkmark \quad$ hasta cinco meses para los que acrediten más de 30 años de servicio.

La propia norma limita la facultad del empleador de notificar la disponibilidad al trabajador en los supuestos de hecho siguientes:

$\checkmark \quad$ durante el período en que esté incapacitado el trabajador temporalmente por enfermedad o accidente de origen común o de trabajo,

$\checkmark$ durante el cumplimiento de misiones internacionalistas, movilizaciones militares $u$ otras movilizaciones de interés económico y social,

$\checkmark \quad$ cuando el trabajador disfruta de sus vacaciones anuales pagadas,

$\checkmark \quad$ durante el período en que esté cumpliendo el Servicios Militar Activo,

$\checkmark \quad$ durante el disfrute de licencia de maternidad $u$ otras licencias legalmente concedidas,

$\checkmark \quad$ cuando está suspendida legalmente su relación laboral,

$\checkmark \quad$ otras situaciones que expresamente la ley autorice.

En estos casos, como requisito formal para el despido, se exige una notificación escrita del empleador, previa consulta con la organización sindical y teniendo en cuenta la recomendación de un "Comité de Expertos" cuya función es la de proponer cuáles son los trabajadores más idóneos para continuar trabajando y ocupar otras plazas y cuáles deben ser declarados disponibles.

La terminación de la relación jurídica laboral y el vínculo laboral en el sector de salud. Términos de aviso previo y derecho de acción.

- La terminación del vínculo laboral en el sector de salud pública: Las relaciones laborales de los técnicos de la salud se incluyen dentro de las "Relaciones Laborales Especiales" que recoge el Código de Trabajo en su artículo 65 , en virtud del cual el Ministerio de Salud Pública tiene la facultad de establecer 
las regulaciones concernientes a la "contratación y otras cuestiones de carácter laboral de los técnicos de la medicina". ${ }^{38}$

Es así que en el sector de salud, el personal "técnico de la medicina" (empleando el término usado en el Código de Trabajo) tiene regulaciones propias, que difieren de lo establecido para el resto de los trabajadores del sector cuyas regulaciones se rigen por la legislación laboral vigente. Este hecho ha servido de punto de partida para que algunos juristas sostengan el criterio de la doble contratación en este sector, a lo que nosotros preferimos llamar un tratamiento diferenciado o especial para el personal propio del sector. La Asamblea Nacional del Poder Popular, el 13 de julio de 1983, en virtud de la Ley 41"Ley de la Salud Pública" facultó al Ministerio de Salud Pública a ubicar, reubicar y promover a los profesionales y técnicos del Sistema Nacional de Salud, así como a establecer las causas y el procedimiento de inhabilitación o suspensión temporal en el ejercicio de la profesión, de aquellos que transgreden gravemente las obligaciones profesionales o éticas que deben observar. El Decreto No. 139 de fecha 4 de febrero de 1988, Reglamento de la Ley 41, establece la prohibición por descalificación del ejercicio de la medicina, además de la inhabilitación, suspensión temporal y rehabilitación de los técnicos y profesionales de la salud. Sin embargo, no hacen referencia a la pérdida o cambio del status laboral por terminación del vínculo laboral con el Ministerio de Salud Pública.

El proceso de formación del personal propio de la salud es planificado, organizado, dirigido y controlado por el Ministerio de Salud Pública, quien determina las especialidades, especializaciones profesionales y técnicas, obreros calificados y otros trabajadores que requiera el país de acuerdo con el desarrollo socioeconómico y los avances científico-técnicos en el campo de la salud. De la misma manera los graduados son ubicados en las entidades del Sistema Nacional de Salud, conforme a las necesidades de cada territorio. El técnico propio del sector salud, inicia su vínculo laboral con el Ministerio desde el tercer año de la carrera, en el caso de la enseñanza de nivel superior. Al terminar sus estudios en los centros docentes, son asignados a las entidades del sistema nacional de salud sin otra formalidad que una Carta de Presentación que las Direcciones Provinciales envían a los municipios con la ubicación preestablecida en un centro asistencial, según las necesidades reales de los servicios médicos. El vínculo entonces se establece doblemente, con el Ministerio de Salud Pública y con las Direcciones Provinciales de Salud, en tanto la relación jurídica laboral se formaliza con la Dirección Municipal de Salud a que pertenezca el centro asistencial donde el técnico sea ubicado, puesto que es el Director Municipal quien tiene jurisdicción y competencia sobre el personal que se le subordina.

Las primeras regulaciones relativas a la conducta del personal propio del sector, las resoluciones ministeriales No. 162 de 22 de abril de 1968 y la No. 8 de fecha 7 de febrero de 1977, que deroga la anterior, y aún está vigente, establecen el procedimiento a seguir para la suspensión e inhabilitación de profesionales y técnicos de la salud que incurran en conductas "lesivas a la dignidad humana de 
los pacientes, a la sensibilidad de sus familiares y al crédito y prestación que este organismo por su función, debe mantener ante el pueblo al cual está obligado a servir". 39

Tal procedimiento es facultad exclusiva del Ministro de Salud Pública, quien puede disponer de forma temporal o definitiva la suspensión en sus cargos 0 inhabilitación en el ejercicio de la medicina, de los profesionales y técnicos propios del sector. Medida esta totalmente independiente de otras medidas administrativas o disciplinarias que pudieran corresponder, a pesar de reconocer en la propia norma que la suspensión o inhabilitación constituyen medidas disciplinarias, por lo que admite la posibilidad de una doble sanción laboral al personal propio del sector de salud. Ambas normas son omisas en cuanto al status laboral del profesional o técnico suspendido o inhabilitado en el ejercicio de la medicina, nótese que cuando la medida es temporal, queda la duda de si se mantiene vinculado al sector ocupando otra tarea o si se suspende el vínculo; situación que adquiere mayor relevancia en la inhabilitación definitiva por las implicaciones que se derivan. Omite también la vigente Resolución 8 de 1977 la posibilidad de impugnar la decisión, o al menos de solicitar su reforma o revisión. ${ }^{40}$

En virtud de la Resolución No. 36 de 4 de marzo de 1983, del Ministerio de Salud Pública, que puso en vigor los lineamientos e indicaciones sobre la política de cuadros en el Ministerio, ${ }^{41}$ se reconocen como cuadros a todo el personal propio del sector de la salud, esto es, a todos los médicos, estomatólogos y demás graduados del nivel superior, otorgándole las categorías de:

- $\quad$ Cuadros técnicos: los médicos, estomatólogo y demás graduados de nivel superior que no ocupan funciones de dirección, docentes o de investigación.

- $\quad$ Cuadros de dirección: todos los que ejercen funciones de dirección, entre los que se encuentran:

$\checkmark \quad$ cuadros científico pedagógicos: los que desarrollan una labor docente en los centros de Educación Superior y Media

$\checkmark \quad$ cuadros científico técnicos: los que desarrollan labores de investigación.

La norma en cuestión remitía al Decreto-Ley 36 de 1980 y su Reglamento, el Decreto-Ley No. 93 de 1981, para la aplicación de medidas disciplinarias, admitiendo así la posibilidad de aplicarles la separación definitiva como forma de terminación de la relación jurídica laboral por iniciativa de la administración, al cometer un trabajador violaciones graves de la disciplina laboral.

Posteriormente, se estableció un procedimiento para disponer la separación del Sistema Nacional de Salud y por tanto, el vínculo con el MINSAP, entre otras medidas. Se regula así la terminación del vínculo laboral con el sector, por iniciativa de la administración al violar el trabajador la disciplina laboral, en virtud del Decreto-Ley 113 "Sobre la disciplina en los Centros Asistenciales del Sistema Nacional de Salud", donde se hace la distinción entre la separación definitiva del 
sector y la separación definitiva del centro asistencial; esta última definitoria del cese de la relación jurídica laboral con el centro donde fuera ubicado el técnico de salud quien, no obstante, conservaba su vínculo con el MINSAP, así como la Dirección Provincial respectiva, que tenía la obligación de reubicarlo. A tales efectos la Ley recogía que "cuando se trata de un profesional o técnico propio de la salud el Ministro de Salud Pública resolverá de conformidad con el procedimiento establecido al amparo de la Ley No. 41 de 13 de julio de 1993."42

Actualmente la terminación del vínculo laboral con el sector, por iniciativa de la administración, en virtud de violación de la disciplina laboral sólo se encuentra preceptuada en el artículo 15 del Decreto-Ley No. 176 de 15 de agosto de 1997, el cual autoriza al Ministerio de Salud Pública, entre otros sectores, a aplicar la separación definitiva del sector ante la ocurrencia de violaciones de la disciplina laboral de suma gravedad que afecten sensiblemente el prestigio del acto de que se trata. ${ }^{43}$

En el momento en que se hace el presente trabajo, se encuentra vigente un procedimiento específico para dar por terminada la relación jurídica laboral en entidades del sector de salud a los técnicos propios, por iniciativa de I administración, al perder el trabajador la idoneidad demostrada. Se trata de la Resolución Ministerial No. 250 del 27 de septiembre de 2006 "Reglamento para la aplicación del principio de idoneidad demostrada en los centros asistenciales del sector de salud". Entre las medidas a aplicar cuando un trabajador pierde la idoneidad demostrada para la ocupación o cargo que desempeña, se encuentra:

$\checkmark \quad$ dar por terminada la relación laboral en el centro: esta medida no determina la pérdida del vínculo laboral con el sector de salud, y por tanto, existe la obligación para la administración de reubicarlo en otro centro.

$\checkmark \quad$ dar por terminada la relación laboral en el centro y solicitud de suspensión temporal o inhabilitación en el ejercicio de la profesión: en este caso tampoco se determina la pérdida del vínculo laboral con el sector, con la obligación a que hicimos referencia anteriormente; en cuanto a la suspensión temporal o inhabilitación en el ejercicio de la profesión se rige por lo ya expuesto, en la Resolución No. 8 de 1977.

Términos de aviso previo y derecho de acción: La primera vez que se reguló el trámite para la terminación del vínculo laboral con el Ministerio de Salud Pública por voluntad del trabajador, fue mediante la Resolución Ministerial No. 54 de fecha 2 de julio de 1999, siguiendo la tendencia de centralizar en la figura del Ministro de Salud Pública las facultades decisorias en cuanto a las relaciones jurídicas laborales del personal propio del sector, siempre sobre la base de garantizar a todos los ciudadanos del país la atención y protección de su salud. Esta disposición fue derogada expresamente por la Resolución Ministerial No. 33 de fecha 25 de abril de 2001, cuyo objeto fue regular el aviso previo y el procedimiento a seguir para dar por terminada la relación jurídica laboral de los profesionales y técnicos graduados en los centros de educación médica media o 
superior, cuando "por su voluntad deciden causar baja de la entidad del sector de la salud en que laboral." 44

Apartándose de la tendencia del legislador, de no contemplar las causales que debe imputar el trabajador que desea dar por terminada la relación jurídica laboral con la entidad, por iniciativa propia, la Resolución No. 33 sí reguló las causas a invocar por el trabajador, limitándolo a constreñirse a ellas como exclusivamente, las mismas eran:

$\checkmark \quad$ para reanudar su "vínculo laboral" en otra entidad del sector, en unidades asistenciales del Ministerio de las Fuerzas Armadas Revolucionarias (MINFAR) o el Ministerio del Interior (MININT) o hacia otras entidades no pertenecientes al sector de la salud en actividades afines a su perfil profesional.

$\checkmark \quad$ para incorporarse a actividades no afines a su perfil ocupacional.

La norma incluye la posibilidad de solicitar la suspensión temporal del vínculo y, además, alegar problemas personales que quedaban sujetos a análisis por el representante de la entidad, de conjunto con la organización sindical.

En el supuesto de que el técnico de salud solicitara la terminación de la relación jurídica laboral para incorporarse a actividades afines en el sector o fuera del mismo, el aviso previo exigido era de:

$\checkmark \quad$ tres meses, para los técnicos de nivel básico;

$\checkmark \quad$ seis meses, para los técnicos de nivel superior.

Estos plazos podían prorrogarse hasta tres meses por una sola vez. De no recibir respuesta el trabajador, en el término del aviso previo, se le reconocía el derecho a dar por terminada la relación jurídica laboral. Única garantía con la que contaban los trabajadores, puesto que a pesar de que el legislador empleó el término de terminación de la relación jurídica laboral, lo cierto es que aquellos que se incorporaban a otras entidades no pertenecientes al sector, perdían, por consecuencia el vínculo con el mismo y a tales efectos se consignaba la causa en el Registro de Profesionales del Sector de salud.

La Resolución Ministerial No. 143 de 17 de julio de 2003, puso en vigor un nuevo procedimiento para la tramitación de la terminación del vínculo laboral con el sector de Salud, disponiendo que "cualquier técnico de nivel superior o facultades de ciencias médicas o de institutos tecnológicos o politécnicos de la salud respectivamente, que soliciten su baja para dejar de laborar en entidades subordinadas al Sistema Nacional de Salud, con el objetivo de incorporarse a actividades afines o no a otros órganos u organismos de la Administración Central del Estado, órganos estatales, entidades nacionales, empresas, uniones de empresas estatales, sociedades mercantiles cubanas, entidades empleadoras de los inversionistas extranjeros, organismos gubernamentales, asociaciones económicas, administrativas, de servicios o de cualquier otra índole, presentará su solicitud fundamentada al Director del centro en que labora para que a través de 
los distintos niveles jerárquicos establecidos y expresando cada uno de ellos sus criterios, lo eleve al que resuelve para su definitiva decisión". 45

Como bien se infiere de la interpretación del precepto, es facultad exclusiva del Ministro de Salud Pública, al acceder o no a dar por terminado el vínculo laboral con el sector y aunque el texto de la resolución no enumere las causas como lo hacía la Resolución No. 33, sí exige que se argumenten, al estipular que: "En todos los casos el que suscribe determina de manera casuística, el término o las condiciones en que puede ser atendida la solicitud, teniendo en cuenta las particularidades, características y elementos concurrentes." ${ }^{46}$

El Ministro tiene amplias facultades, al tener la posibilidad de decidir a quien le aprueba la solicitud y a quien se la deniega, tampoco está sujeto a un término legal por cuanto la Resolución No. 33, que establecía los términos de aviso previo con la consiguiente garantía de conceder el derecho al trabajador de dar por terminada la relación jurídica laboral con la entidad en cuestión o, el vínculo con el sector, una vez transcurrido el término de aviso previo sin recibir respuesta, quedó expresamente "abrogada" en virtud de la Resolución Ministerial No. 144 de 17 de julio de 2003, al considerar el Ministro que la primera constituía un acto jurídico realizado en contra de los intereses del estado y de la sociedad, conforme al artículo 67, inciso a) del Código Civil, razón que aconsejaba posponer la ejecución de todos los procedimientos de aviso previo y demás acciones presentadas al amparo de la resolución No. 33 del 2001 y así evitar la posibilidad de afectaciones a los servicios de salud que se brindan a la población. ${ }^{47}$

Dentro de los técnicos propios del sector, aquellos que ocupan cargos de dirección, son tratados conforme a lo dispuesto en los Decretos-Leyes 196 y 197, ambos de 1997; sin embargo, la renuncia o la democión no surten los mismos efectos que para el resto de los trabajadores de otros sectores, puesto que no pierden el vínculo con el Ministerio de Salud Pública y al existir la obligación de las respectivas Direcciones Provinciales de proporcionarles ubicación, o sea, pueden perder la condición de funcionarios o dirigentes pero no el vínculo con el sector de salud.

Para conocer la valoración de los técnicos objeto de la legislación propia del sector de salud, realizamos 300 encuestas en los diferentes centros asistenciales del municipio Bayamo, el $83.3 \%$ de ellos consideran que el procedimiento para conceder las bajas del sector, por solicitud propia, no es el más adecuado, pues el término se dilata excesivamente: de ellos un 4\%, 12 trabajadores, han solicitado la terminación del vínculo laboral, 3 de ellos se encuentran esperando hace cuatro años, 6 llevan en espera tres años, y el resto, dos años; sólo dos se han quejado directamente al Ministerio de Salud Pública, al Departamento de Atención a la Población y dos lo han hecho ante la Dirección Provincial, obteniendo como respuesta que deben esperar a la decisión del Ministro, mientras que uno requirió 
de los servicios de un abogado del Bufete Colectivo y todavía no ha obtenido respuesta. ${ }^{48}$

Si nos remitimos a las normas del Código Civil vigente, como supletorias de las relaciones contempladas en la legislación especial, encontramos la regulación del derecho de acción como garantía de la protección de la relación jurídica, "siempre que sea autorizada expresamente por la Ley". ${ }^{49}$ Como requisito fundamental para ejercer la acción, se exige que esté expresamente regulado o reconocido por una norma jurídica; el Código de Trabajo, por su parte, reconoce expresamente este derecho del trabajador contra las medidas disciplinarias aplicadas por la administración, de la misma manera en que se pronuncian las legislaciones laborales vigentes en materia de responsabilidad laboral y de reclamación de derechos. Sin embargo, para los trabajadores que deciden dar por terminada la relación jurídica laboral por iniciativa propia, la regulación del término de aviso previo, a nuestro modo de ver, deviene en su garantía al constituirse en un aviso legal anticipado del día en que dará por terminada tal relación, sin que incurra en responsabilidad alguna. Al no tener el Ministerio de Salud Pública una norma que reconozca el término del aviso previo ni el derecho de acción del trabajador contra la decisión administrativa de establecer el término en que dará por terminado el vínculo con el sector no podrá recurrir a la norma civil, si la misma exige su reconocimiento en la legislación especial. Por tanto el técnico propio del sector no puede recurrir legalmente la decisión que tome la autoridad facultada respecto a la modificación de su status laboral, tan sólo pueden hacer uso de su derecho constitucional a la queja o a peticiones recogidos en el artículo 63 de la Constitución de la República, ante la propia autoridad facultada para decidir el status laboral del trabajador.

La terminación de la relación jurídica laboral con la entidad no entraña el cese del vínculo laboral con la Dirección Provincial respectiva ni con el Ministerio de Salud Pública; el vínculo se disuelve por iniciativa del trabajador, cuando decide solicitar su "baja" del sector y, por tanto, del Registro de Graduados; por iniciativa de la administración, con la aplicación de la medida disciplinaria de separación del sector, al incurrir un técnico propio en violación grave de la disciplina laboral, o cuando se inhabilita de forma permanente a un profesional en el ejercicio de su profesión, por las mismas causas señaladas.

Las normas del Ministerio de Salud Pública son omisas en cuanto al término de aviso previo, le otorgan al Ministro plenas facultades para decidir si aprueba o no las solicitudes de dar por terminado el vínculo con el sector por iniciativa del trabajador, así como el término en que tomará la decisión. Tampoco existe la posibilidad, para el técnico propio del sector, de accionar contra tales decisiones. Tales desregularizaciones provocan un gran descontento entre el personal propio del sector, fundamentalmente en aquellos que deciden terminar su vínculo laboral con el Ministerio para incorporarse a otras actividades, afines 0 no, en otros sectores. 
Resulta menester, por tanto, modificar la legislación especial vigente del Ministerio de Salud Pública para atemperarla, en la medida de lo posible, a la legislación sustantiva o a las tendencias actuales del legislador cubano, sin que por ello se menoscabe el derecho de todo ciudadano a que se le garantice la atención a su salud.

\section{CONCLUSIONES}

Primera: El procedimiento para dar por terminado el vínculo laboral con el sector de salud, por iniciativa del trabajador, dista por completo de la tendencia de la legislación general vigente y especifica emitida por el Organismo de la Administración Estatal con Jurisdicción y Competencia el Ministerio de Trabajo y Seguridad Social, que lejos de la facultad que la Ley no. 41 le otorgó al Ministerio de Salud Pública en razón del principio de estabilidad laboral, esta provocando descontentos ante la existencia de una desregularización en cuanto a términos de aviso previo y derecho de acción del trabajador contra la decisión administrativa de dilatar los términos y aprobar o no la terminación del vínculo laboral con el sector.

Segunda: Se vulnera por el Ministerio de Salud los derechos constitucionales de la persona en Cuba para el personal técnico que forma en sus instituciones, su nos ajustamos a la letra de la Carta Magna.

\section{RECOMENDACIONES}

Primera: Que la Comisión de Asuntos Constitucionales y Jurídicos de la Asamblea Nacional del Poder Popular y el Ministerio de Trabajo y Seguridad Social someta a una valoración exhaustiva la legislación especial del Ministerio de Salud Pública para la terminación del vínculo laboral por iniciativa del trabajador, a los efectos de determinar su utilización y legalidad.

Segunda: Que el Ministerio de Salud Pública realice una revisión exhaustiva del procedimiento actual para dar por terminado el vínculo con el sector por iniciativa del trabajador, y lo atempere a las regulaciones establecidas en la legislación general dictada por el Ministerio de Trabajo y Seguridad Social, disponiendo un término de aviso previo en correspondencia con la complejidad de la labor del técnico o su grado de profesionalidad, con los efectos que le reconoce la legislación laboral vigente en nuestro derecho positivo.

Tercera: Que el Ministerio de Justicia realice la revisión y valoración exhaustiva de la legislación especial que dicta el Ministerio de Salud Pública, para que no entre en contradicción con los principios universales del derecho y de la Constitución Cubana. 


\section{BIBLIOGRAFIA}

\section{- REFERENCIAS JURÍDICAS:}

1. Ley No. 41 De la Salud Pública, de fecha 13 de julio de 1983, artículo 3.

2. Ibídem. art. 4.

3. Ley No. 49 Código de Trabajo, de fecha 24 de diciembre de 1984, artículo 65

4. Viamontes Guilbeaux, Dra. C. Eulalia. Derecho Laboral Cubano Teoría y Legislación, segunda edición, Tomo I, editorial Félix Varela, La Habana, 2007. Página 83.

5. - --, Instituciones del derecho laboral cubano. La Habana. 2008.

6. Ver: Ibídem, página 28.

7. Ver: Ibídem, página 84

8. Ley 49, Código de Trabajo, Editorial Pueblo y Educación. La Habana, 1982.

9. Nápoli, Rodolfo. Las Relaciones Laborales en el Siglo XXI. Fortalezas de la Ley de Contrato de Trabajo. Tomado de http://www.calp.org.ar/Instituc/Institutos/laboral.

10. Código del Trabajo de Chile, artículo 3, disponible en el sitio http://colegioabogados.org/normas/codice/

11. Guido Machiavello C., "Derecho del Trabajo", Teoría Jurídica y Análisis de las actuales normas chilenas. Tomo I, págs. 173 y 174, tomado de www.ot.gob.cl.

12. Ugarte Cataldo, José Luis. "La Subordinación Jurídica y los Desafíos del nuevo mundo del trabajo". Gaceta Laboral disponible en http://www.serbi.luz.edu.ve

13. Botero Holguín, Juan Felipe. "Nueva Ley de Contratos de Trabajo en la RPC". Disponible en http://www.casaasia.es

14. Cabanellas, Guillermo, Tratado de Derecho Laboral, Buenos Aires, Editorial Heliatra S.R.L., tercera edición, 1989, Tomo II, volumen 3, página 362.

15. Ibídem. página 29

16. Mesén Montoya, Julio César. Dictamen 102 del 26/05/1999. Disponible en www.pgr.go.cr/scij/busqueda/normativa/pronunciamiento

17. Ley Orgánica del Trabajo, disponible en www.analitica.com/biblioteca/congreso_venezuela.

18. Couture, Eduardo J."Fundamentos de Derecho Procesal Civil". Disponible en www.avizora.com

19. Ibídem.

20. Couture, Eduardo J."Fundamentos de Derecho Procesal Civil". Disponible en www.avizora.com. 
21. Ibídem.

22. Ley Orgánica del Trabajo, artículo 98, disponible en www.analítica.com/biblioteca/congreso_venezuela.

23. Ver: Ibídem, art. 99

24. Ver: Ibídem, art. 100

25. Ibídem.

26. Ley Orgánica del Trabajo, artículo 98, disponible en www.analítica.com/biblioteca/congreso_venezuela.

27. Ver: Ibídem, art. 99

28. Ver: Ibídem, art. 100

29. Código del Trabajo de Chile, tomado de http//egoups.com.

30. Ley Orgánica del Trabajo, artículo 104, disponible en www.analítica.com/biblioteca/congreso_venezuela

31. Ver: Ibídem, art. 107

32. Ley 19.378, disponible en http//egoups.com

33. Código de Trabajo de Argentina, tomado de www.foceconsultoriaespecializada.com.mx

34. Ley 49 Código de Trabajo, artículo 28, páginas 15 y 16.

35. Ley 82 De los Tribunales Populares, de 11 de julio de 1997, artículo 66. Publicado en la Gaceta Oficial de 14 de julio de 1997. Edición Extraordinaria

36. Ley 83 De la Fiscalía General de la República, de 11 de julio de 1997. Publicado en la Gaceta Oficial de 14 de julio de 1997. Edición Extraordinaria

37. Resolución No. 35 del Ministerio de Trabajo y Seguridad Social de fecha 7 de octubre de 2010, artículo 1 inciso a). Publicado en la Gaceta Oficial del 8 de octubre de 2010, Edición Extraordinaria Especial.

38. Viamontes Guilbeaux, Dra. C. Eulalia. Derecho Laboral Doctrina y Legislación. Segunda Edición. Tomo I. Editorial Félix Varela. Pág. 178.

39. Ibídem a la anterior. Página 181.

40. Ver: Ibídem.

41. Álvarez Tabío, Fernando. Comentarios a la Constitución Socialista. Editorial Pueblo y Educación. La Habana, 1988. página 228.

42. Ibídem página 230

43. Ley 49 Código de Trabajo, de fecha 24 de diciembre de 1984, artículo 65.

44. Resolución Ministerial No. 8 de 1977. Dirección Jurídica. Archivos MINSAP. No obstante, tampoco niega la posibilidad de establecer recurso en su contra, lo cierto es que el Ministerio de Trabajo y Seguridad Social, a través de su legislación 
remite a la legislación propia del sector en cuanto a la solución de conflictos, entre otras materias. (Nota de los autores)

45. Disposiciones del Ministro de Salud Pública. Dirección de Cuadros. Archivo del MINSAP.

46. Decreto-Ley No. 113, de 13 de julio de 1989, artículo 14. Legislación del MINSAP. Archivo del MINSAP.

47. Este artículo fue modificado por el Decreto-Ley No. 253 de 16 de septiembre de 2007. Publicado en la Gaceta Oficial No. 50 de 1 de noviembre de 2007. Edición Extraordinaria

48. Resolución 33 de 25 de abril de 2001, Gaceta Oficial No. 69, Edición Ordinaria

49. Resolución No. 143 del MINSAP, de 17 de julio de 2003, Resuelvo Primero. Publicada en Gaceta Oficial No. 49 de 18 de noviembre de 2003. Edición Ordinaria.

50. Resolución No. 143 del MINSAP de 17 de julio de 2003, Resuelvo Segundo. Publicada en Gaceta Oficial No.49, de 18 de noviembre de 2003. Edición Ordinaria.

51. Resolución No. 144 del MINSAP de 17 de julio de 2003, Resuelvo Segundo. Publicada en Gaceta Oficial No.49, de 18 de noviembre de 2003. Edición Ordinaria

52. Los datos aquí consignados se obtuvieron de la encuesta directa a los técnicos propios del sector; no pueden ofrecerse datos exactos sobre la cantidad de técnicos que se encuentran en espera de la decisión por parte del Ministro de Salud Pública, así como el término de tramitación por cuanto estos datos se computan junto a las solicitudes de liberación por abandono del país, los que son de carácter limitado para el uso exclusivo de la Direcciones Provinciales de Salud, según las indicaciones ministeriales. (Nota de los autores)

53. Ley 59 Código Civil, de 16 de julio de 1987, Título VII, artículos 110 y 111.

\section{LIBROS}

- Álvarez Tabío, Fernando: Comentarios a la Constitución Socialista, Editorial Pueblo y Educación, 1988.

- Dirección de Cuadros MINSAP: Disposiciones del Ministerio de Salud Pública, La Habana, 1983.

- $\quad$ Fernández Bulté, Julio: Historia del Estado y el Derecho en Cuba, Editorial Félix Varela, La Habana, 2004.

- Guillén Landrián, Francisco y otros: Derecho Laboral. Parte General, ENSPES, La Habana, 1985. 
- Viamontes Guilbeaux, Eulalia: Derecho Laboral Cubano. Teoría y Legislación, segunda edición, Editorial Félix Varela, La Habana, 2007.

- $\quad$--, Instituciones del Derecho Laboral Cubano. 2007. Edición Digital. Cubalex. Universidad de La Habana. Cuba. 2007.

\section{LEGISLACION}

\section{Leyes:}

- $\quad$ Constitución de la República, de fecha 24 de febrero de 1976.

- $\quad$ Ley No.7 Ley de Procedimiento Civil, Administrativo y Laboral, de fecha 19 de agosto de 1977.

- $\quad$ Ley No. 41 De la Salud Pública, de fecha 13 de julio de 1983.

- $\quad$ Ley No. 49 Código de trabajo, de fecha 24 de diciembre de 1984.

- $\quad$ Ley No. 59 Código Civil, de fecha 16 de julio de 1987.

- $\quad$ Ley No. 82 De los Tribunales Populares, de fecha 11 de julio de 1997.

- Ley No. 83 De la Fiscalía General de la República, de fecha 11 de julio de 1997.

\section{Decretos-Leyes:}

- Decreto-Ley No. 113 Sobre la Disciplina de los Centros Asistenciales del Sistema Nacional de Salud, de fecha 6 de junio de 1989.

- Decreto-Ley No. 176 Sistema de Justicia Laboral, de fecha 15 de agosto de 1997.

- $\quad$ Decreto-Ley No. 196 Sistema de Trabajo con los Cuadros del Estado y del Gobierno, de fecha 15 de octubre de 1999.

- Decreto-Ley No. 197 Sobre las Relaciones Laborales del Personal Designado para ocupar Cargos de Dirigentes y de Funcionarios, de fecha 15 de octubre de 1999.

\section{Decretos:}

- Decreto No. 139 Reglamento de la ley de la Salud Pública, de fecha 4 de febrero de 1988.

\section{Resoluciones:}

- $\quad$ Resolución Ministerial No. 8 del MINSAP, de fecha 7 de febrero de 1977.

- $\quad$ Resolución Ministerial No. 36 del MINSAP, de fecha 4 de marzo de 1983.

- $\quad$ Resolución No. 51 del Comité Estatal de Trabajo y Seguridad Social, de fecha 12 de diciembre de 1988: GOO No.90 de 30 de diciembre de 1988.

- $\quad$ Resolución Conjunta No. 1del Ministerio de Trabajo y Seguridad SocialTribunal Supremo Popular, de fecha 4 de diciembre de 1997. 
- $\quad$ Resolución Ministerial No. 33 del MINSAP, de fecha 25 de abril de 2001.

- $\quad$ Resolución Ministerial No.143 del MINSAP, de fecha 17de julio de 2003: GOO No. 49 de 18 de noviembre de 2003, p 774.

- $\quad$ Resolución Ministerial No.144 del MINSAP, de fecha 17de julio de 2003: GOO No. 49 de 18 de noviembre de 2003, pp 774-775.

- $\quad$ Resolución Ministerial No. 8 del MTSS, de fecha 10 de marzo de 2005.

- $\quad$ Resolución Ministerial No.250 del MINSAP, de fecha 27de septiembre de 2006: GOO No. 88 de 3 de noviembre de 2006, pp 1607-1614.

\section{TESIS CONSULTADAS}

- $\quad$ Quesada Santiesteban, Juan Guillermo: La Revolución Integral de la Salud y su Impacto en la Legislación Laboral Cubana, tesis en opción a la especialidad en Asesoría Jurídica, Universidad de Oriente, Facultad de Derecho, 2007. República de Cuba. Disponible en EUMENET. Universidad de Málaga. España.

\section{BIBLIOGRAFIA ELECTRONICA}

- ¿Como es la aplicación del preaviso por parte del trabajador?, disponible en: http://www.bonila.com/Como-es-la-aplicacion-del-preaviso.html

- Normativa laboral. Dirección del Trabajo. Gobierno de Chile, disponible en: www.dt.gob.cl/legislacion/1611/printer-84925.html

- $\quad$ Perdomo, Juan Rafael: Ponencia, disponible en: www.tsj.gov.ve/decisiones /scs/Noviembre/c315-201101-01379.htm

- Jurisprudencia Chilena: 25.05.04 - Rol No. 2621-03, disponible en: www.jurisconsultor. blogspot.com/2007/07/250504-rol-n-2621-03.html

- La efectividad de la legislación laboral en América Latina, disponible en: www.ilo.org/public/spanish/bureau/inst/download/dp18107.pdf

- Elías Mantero, Fernando: Reglas para desarrollar una adecuada contratación laboral, disponible en:

- Las Relaciones Laborales en el Siglo XXI, disponible en: www.calp.org.ar/Instituc/Institutos/laboral/RL21.doc

- La Relación Laboral, disponible en: www.peting.ucsc.cl/ico/ Cursos\%20I\%20Sem/ICO1102/Relacion\%20Laboral\%20y\%20Contrato\%20de\%20 Trabajo.doc

- $\quad$ Analizando el despido, disponible en: www.universidadperu.com/articuloanalizando-el-despido-universidad-peru.php

- Terminación de la relación de trabajo, despido y cese», Ginebra, 1961, disponible en: www.cepc.es/rap/Publicaciones/Revistas/10/RPS_062_005.pdf 
- Fundamentos de Derecho Procesal Civil, disponible en: www.gandhi.com.mx/index.cfm/id/Producto/dept/libros/pid/307493

- Ugarte Cataldo, José Luis: La subordinación jurídica y los desafíos del nuevo mundo del trabajo, disponible en: www.dt.gob.cl

- Presunción de la existencia de una relación labora, disponible en: www.gerencie.com/presuncion-de-la-existencia-de-una-relacion-laboral.html

- $\quad$ Preaviso, disponible en: www.asesorlaboral.com.ar/preaviso.htm

- Terminación del contrato de trabajo, disponible en: www.consultaslaborales.blogspot.com/2007/05/terminacion-del-contrato-de-trabajo.html

- Perú. Síntesis de la legislación laboral, disponible en: www.ilo.org/dyn/natlex/docs/WEBTEXT/47564/65081/S97PER01.htm

- Suspensión y pérdida del vínculo laboral, disponible en: www.ceprocabc.com/legislacion_laboral_detalles.asp?ld

- Contrato de trabajo o subordinación, disponible en: www.universidadperu.com/articulo-contrato-de-trabajo-o-subordinacionuniversidad-peru.php

- Relación de dependencia: aspectos controvertidos, disponible en: www.geocities.com/marcosk2k/relaciondedependencia.ppt

- La subordinación jurídica, disponible en:

www.es.wikipedia.org/wiki/Derecho_laboral 